\title{
$\mathrm{n}^{\circ}$ 2020-05
}

\section{Taking off into the Wind: Unemployment Risk and State-Dependent Government Spending Multipliers}

\author{
Julien ALBERTINI' \\ Stéphane AURAY ${ }^{2}$ \\ Hafedh BOUAKEZ ${ }^{3}$ \\ Aurélien EYQUEM ${ }^{4}$
}

Les documents de travail ne reflètent pas la position du CREST et n'engagent que leurs auteurs.

Working papers do not reflect the position of CREST but only the views of the authors.

\footnotetext{
${ }^{1}$ Univ Lyon, Université Lumière Lyon 2, GATE UMR 5824, F-69130 Ecully, France; e-mail: julien.albertini@univ-lyon2.fr.

${ }^{2}$ CREST-ENSAI and ULCO; e-mail: stephane.auray@ensai.fr.

${ }^{3}$ Department of Applied Economics and CIREQ, HEC Montréal, 3000 chemin de la Côte-SainteCatherine,Montréal, Québec, Canada H3T 2A7; e-mail: hafedh.bouakez@hec.ca.

${ }^{4}$ Univ Lyon, Université Lumière Lyon 2, GATE UMR 5824, F-69130 Ecully, France, and Institut Universitaire de France; e-mail: aurelien.eyquem@univ-lyon2.fr.
} 


\title{
Taking off into the Wind: Unemployment Risk and State-Dependent Government Spending Multipliers*
}

\author{
Julien Albertini ${ }^{\dagger} \quad$ Stéphane Auray ${ }^{\ddagger} \quad$ Hafedh Bouakez $^{\S} \quad$ Aurélien Eyquem ${ }^{\llbracket}$
}

First draft: February 2018

This version: March 2020

\begin{abstract}
We propose a model with involuntary unemployment, incomplete markets, and nominal rigidity, in which the effects of government spending are state-dependent. An increase in government purchases raises aggregate demand, tightens the labor market and reduces unemployment. This in turn lowers unemployment risk and thus precautionary saving, leading to a larger response of private consumption than in a model with perfect insurance. The output multiplier is further amplified through a composition effect, as the fraction of high-consumption households in total population increases in response to the spending shock. These features, along with the matching frictions in the labor market, generate significantly larger multipliers in recessions than in expansions. As the pool of job seekers is larger during downturns than during expansions, the concavity of the job-finding probability with respect to market tightness implies that an increase in government spending reduces unemployment risk more in the former case than in the latter, giving rise to countercyclical multipliers.
\end{abstract}

Keywords: Government spending, Multipliers, Precautionary saving, State dependence, Unemployment risk.

JEL Class.: D52, E21, E62.

${ }^{*}$ We thank Sehyoun Ahn, Paul Beaudry, Florin Bilbiie, Giacomo Candian, Marco Cozzi, Mick Devereux, Giovanni Gallipoli, François Langot, Pascal Michaillat, Pierre-Carl Michaud, Makoto Nakajima, Jordan Roulleau-Pasdeloup, Romanos Priftis, Rigas Oikonomou, Xavier Ragot, and seminar participants at the OFCE, the University of Le Mans, the University of Lausanne, the University of British Columbia, and the University of Ottawa for helpful comments and suggestions. Financial support from the FRQSC and the HEC Montréal Foundation is gratefully acknowledged.

${ }^{\dagger}$ Univ Lyon, Université Lumière Lyon 2, GATE UMR 5824, F-69130 Ecully, France; e-mail: julien.albertini@univ-lyon2.fr.

${ }^{\ddagger}$ CREST-Ensai and ULCO; e-mail: stephane.auray@ensai.fr.

${ }^{\S}$ Department of Applied Economics and CIREQ, HEC Montréal, 3000 chemin de la Côte-Sainte-Catherine, Montréal, Québec, Canada H3T 2A7; e-mail: hafedh.bouakez@hec.ca.

"Univ Lyon, Université Lumière Lyon 2, GATE UMR 5824, F-69130 Ecully, France, and Institut Universitaire de France; e-mail: aurelien.eyquem@univ-lyon2.fr. 


\section{Introduction}

An important branch of the recent empirical literature on fiscal policy has focused on the question of whether the macroeconomic effects of government spending depend on the amount of slack in the economy. Building on the original work of Auerbach and Gorodnichenko (2012a,b), several empirical studies relying on non-linear time-series models find that government spending has a significantly larger effect on aggregate output during recessions than during expansions, with a multiplier that often exceeds 1 in the former state. ${ }^{1}$ Based on a meta-regression analysis of 98 empirical studies, and controlling for regime dependence, Gechert and Rannenberg (2018) also conclude that spending multipliers are much higher during downturns.

This is a topic, however, where measurement is still far ahead of theory, as there are very few theoretical models capable of generating meaningful asymmetry in the effects of government spending in good and bad states. ${ }^{2}$ Michaillat (2014) proposes a model in which search and matching frictions in the labor market imply that public employment crowds out private employment less in recessions than in expansions because it generates a smaller increase in labor-market tightness. ${ }^{3}$ Canzoneri, Collard, Dellas, and Diba (2016) develop a model with countercyclical variations in the bank intermediation cost, making the spread more sensitive to fiscal policy during recessions than during expansions. Finally, Shen and Yang (2018) generate state dependence in a model with involuntary unemployment subject to a downward nominal wage rigidity constraint. All of these papers, however, assume perfect risk sharing among consumers, neglecting two important channels that can shape the aggregate effects of government spending and their dependence on the business cycle: unemployment risk and changes in the composition of aggregate consumption resulting from changes in the fraction of unemployed agents.

When insurance markets are incomplete, unemployment risk gives rise to a precautionary-saving motive that affects consumption decisions and thus the spending multiplier. Furthermore, since employed households earn and consume more on average than unemployed households, a change in the unemployment rate will be associated with a change in aggregate consumption, even if

\footnotetext{
${ }^{1}$ Examples include Bachmann and Sims (2012), Mittnik and Semmler (2012), Baum, Poplawski-Ribeiro, and Weber (2012), Candelon and Lieb (2013), Fazzari, Morley, and Panovska (2015), and Furceri and Li (2017). Owyang, Ramey, and Zubairy (2013) find some evidence of state dependence in Canada but not in the U.S.

${ }^{2}$ Numerous theoretical studies have shown that the size of the spending multiplier can be substantially larger during episodes in which the nominal interest rate is stuck at its zero lower bound (ZLB) than in periods where the ZLB constraint in not binding (e.g., Eggertsson (2011), Woodford (2011), and Christiano, Eichenbaum, and Rebelo (2011)). While ZLB episodes are usually accompanied by severe recessions, the larger multipliers found at the ZLB essentially reflect monetary-policy-regime dependence rather than state dependence per se, as the proposed models are either linear or lack the type of non-linearity required to generate countercyclical multipliers outside the ZLB. One exception is the model developed by Roulleau-Pasdeloup (2016), which implies that about two thirds of the spending multiplier at the ZLB is accounted for by the fact that hiring is easier in recession than in expansion. Albeit countercyclical, however, the multiplier remains smaller than 1 even in deep recessions.

${ }^{3}$ Michaillat and Saez (2018) show that a similar mechanism leads to countercyclical government purchase multipliers (as opposed to public employment multipliers) in a model with search and matching frictions in the goods market.
} 
the per capita consumption of unemployed and employed households remain unchanged. In this paper, we show that these two ingredients lead to substantial asymmetry in the aggregate effects of government spending in recession and expansion, implying state-dependent spending multipliers.

We propose a model of search and matching frictions in the labor market, in which unemployed risk is not fully insurable. The model also features price and real wage rigidity, an intensive margin of labor adjustment, and nominal government debt. Our framework shares several features with those developed by Ravn and Sterk (2016), Challe (2018), and Gornemann, Kuester, and Nakajima (2016), who, however, focus on the implications of unemployment risk for the conduct of monetary policy. ${ }^{4}$ Importantly, we relax the assumption of zero net aggregate supply of bonds, made by Ravn and Sterk (2016) and Challe (2018), which leads to a degenerate wealth distribution in equilibrium, such that changes in unemployment risk and precautionary saving are only accommodated by changes in the equilibrium real interest rate. Instead, in our economy, the supply of bonds varies endogenously, giving rise to a non-degenerate distribution of households along government bond holdings, and introducing an additional source of income heterogeneity across households. The model is calibrated to represent a sclerotic labor market akin to that prevailing in the majority of European economies, characterized by relatively low separation and job-finding rates and a relatively high replacement rate. In a rigid labor market, workers' exposure to unemployment risk has an important bearing on their precautionary saving, and policies that can alleviate this risk are likely to induce a large reduction in aggregate saving and thus a large response of aggregate consumption.

Before assessing the degree of state dependence of the effects of government spending, we evaluate those effects when the economy is initially in the steady state. The purpose of this exercise is to ensure that the model is capable of generating empirically plausible average spending multipliers. Under our benchmark calibration, we obtain a present-value output multiplier of 0.86, well within the range of available estimates (see Ramey (2019) for a recent overview). This value is roughly $35 \%$ larger than that obtained in an otherwise identical economy with complete insurance markets (0.64). By raising aggregate demand in an economy with nominal rigidity, higher public spending raises both employers' future profits and the rate at which those profits are discounted. The net effect, however, is an increase in the present discounted value of profits, which raises the marginal value of a filled position and leads firms to post more vacancies. As a result, unemployment falls, thus lowering unemployment risk and reducing precautionary saving, which fuels the rise in aggregate demand and further lowers unemployment. ${ }^{5}$ At the same time, the fall

\footnotetext{
${ }^{4}$ Krusell, Mukoyama, and Şahin (2010) were the first to introduce unemployment risk in a model with a frictional labor market.

${ }^{5}$ Beaudry, Galizia, and Portier (2018) propose an alternative model in which unemployment risk and precautionary saving also lead to an amplification of the effects of demand shocks. However, unlike the mechanism put forward in our model, which relies on nominal price rigidity, theirs is based on the existence of some coordination failure that limits gains from trade between individuals.
} 
in the unemployment rate increases the share of high-consumption households in total population. Aggregate output therefore increases by a larger amount than in a counterfactual economy in which unemployment risk is fully insurable. The difference in the output multiplier between the incomplete- and complete-market economies suggests that alleviating idiosyncratic income risk can be an important source of amplification of the aggregate effects of fiscal policy.

We then evaluate the state dependence of the spending multiplier by comparing the effects of an increase in government spending in recession and expansion. These states are generated by adverse and favorable productivity shocks that occur while the economy is in the steady state. Positive realizations of the shock raise labor productivity by $1 \%$, while negative realizations reduce it by the same percentage. Under our benchmark parameter values, the conditional output multiplier is 0.82 in expansion and 1.07 in recession - a difference of roughly 30\%. This state dependence results from three interconnected features: the matching frictions, the precautionary motive, and the composition effect. As the pool of job seekers is larger during downturns than during expansions, the concavity of the job-finding probability with respect to market tightness implies that employment increases more in the former case than in the latter, in response to a given increase in government spending. Because unemployment risk is reduced substantially more when government spending occurs while the economy is in recession, unemployed households curtail their precautionary saving by a larger amount. The larger reduction in the fraction of low-consumption households in total population further contributes to the larger difference in the output multiplier between recession and expansion.

More generally, we show that the spending multiplier is decreasing and highly convex in the size of the productivity shock. That is, it increases exponentially with the severity of the recession but decreases fairly linearly with the size of the expansion. This strong curvature implies that the state dependence of the effects of government spending becomes increasingly salient when businesscycle fluctuations become more volatile, exhibiting higher peaks and deeper troughs. We also show that a counterfactual economy that abstracts from unemployment risk (via complete insurance markets) severely understates the extent of state dependence, implying a difference in the output multiplier of $4 \%$ between recession and expansion under our benchmark calibration. An economy with fully flexible prices, on the other hand, yields a larger multiplier in expansion than in recession - implying an inverted state dependence - as it predicts that an increase in government spending raises unemployment. Price flexibility implies that employers' current and future profits remain constant but are discounted at a higher rate, causing a fall in the value of a filled job and in vacancy posting.

Recent studies based on models with heterogeneous agents and sticky prices — which have come to be known as HANK models - have shown that the distributional effects of first- and secondmoment shocks can alter significantly their transmission mechanisms and thus their aggregate 
implications. ${ }^{6}$ In a related paper to ours, Hagedorn, Manovskii, and Mitman (2019) extend this class of models by allowing for wage rigidity to evaluate the size of the fiscal multiplier. Our model, however, differs from Hagedorn et al.'s in that the source of household heterogeneity in our paper is not an (exogenous) idiosyncratic level of productivity but the employment status of households. We believe that there are three advantages to the latter approach. First, it implies that income risk is endogenous and is affected by aggregate variables, which brings about a feedback loop that amplifies both the aggregate effects of government spending shocks and their state dependence. Second, the composition effect can be directly mapped into the relative fraction of unemployed households, which is readily observable in the data. Finally, allowing employment to adjust both along the intensive and extensive margins enables us to generate spending multipliers that are more in line with existing empirical estimates than the multipliers obtained by Hagedorn, Manovskii, and Mitman (2019). A version of our economy in which hours worked are constrained to remain constant underestimates the average output multiplier by more than $60 \%$.

Our paper is also related to the literature that evaluates the spending multiplier within twoagent New Keynesian (TANK) models, in which a constant fraction of households are hand-tomouth, consuming their current disposable income at any point in time (e.g., Galí, López-Salido, and Vallés (2007) and Bilbiie (2008)). A typical prediction of TANK models is that the output multiplier increases with the fraction of hand-to-mouth households. Our framework models household heterogeneity in a more compelling way, allowing the fractions of low- and high-consumption agents to vary endogenously, and taking into account idiosyncratic income risk. The resulting transmission mechanism of government spending shocks differs markedly from that embedded in TANK models.

The rest of the paper is structured as follows. Section 2 presents the model economy, describes the benchmark calibration and solution method, and discusses the steady-state distributions, policy functions, and MPCs. Section 3 discusses the average (unconditional) effects of government spending shocks both in the benchmark economy and in four counterfactual versions of the model, in which we $(i)$ neutralize the composition effect, (ii) allow for complete insurance markets, (iii) abstract from the intensive margin of labor adjustment, and ( $i v)$ assume fully flexible prices. It also studies the case in which the increase in government purchases is financed exclusively by lump-sum taxes rather than by issuing new public debt as in the benchmark economy. Section 4 discusses the effects of government spending shocks conditional on negative and positive productivity shocks. It also studies the sensitivity of the results to perturbations in the values of some key parameters, and to an alternative calibration that represents a high-turnover labor market such as that characterizing the U.S. economy.

\footnotetext{
${ }^{6}$ For instance, Kaplan, Moll, and Violante (2018), and Kaplan and Violante (2018) focus on monetary policy shocks, while Bayer, Luetticke, Pham-Dao, and Tjaden (2019) focus on uncertainty shocks. Bilbiie (2019) analytically characterizes the conditions about household heterogeneity under which the aggregate effects of shocks and policies are amplified or dampened.
} 


\section{Model}

The model is a new-Keynesian economy with search and matching frictions in the labor market and incomplete insurance markets. The final (consumption) good is produced by assembling differentiated varieties produced by monopolistically competitive retailers using intermediate goods. Retailers set prices subject to quadratic adjustment costs, and intermediate-good producers hire workers in a frictional labor market by posting vacancies subject to vacancy-posting costs. Labor can also adjust along the intensive margin through changes in hours worked. For simplicity, the model abstracts from capital. The only asset available for self-insurance is a one-period nominal government bond, in positive net supply, through which the government can run budget deficits/surpluses over the business cycle, since it is not tied by a balanced-budget requirement.

\section{$2.1 \quad$ Households}

The economy is populated with a unit-size continuum of heterogeneous households. An endogenously determined fraction $\left(1-u_{t}\right)$ of households is employed and a fraction $u_{t}$ is unemployed. Let $\mathcal{E}_{t}^{i}=\{e, u\}$ denote the set of possible employment statuses of household $i$, with $e$ and $u$ referring to, respectively, employment and unemployment. Household $i$ maximizes

$$
\mathbb{E}_{t}\left\{\sum_{s=t}^{\infty}\left(\frac{1}{1+\rho}\right)^{s-t}\left(\log \left(c_{s}^{i}\right)-\mathbb{1}_{e}^{i} \omega \frac{\ell_{t}^{1+\psi}}{1+\psi}-\left(1-\mathbb{1}_{e}^{i}\right) \Phi\right)\right\}, \quad \rho>0, \psi>0, \omega>0
$$

where $c_{t}^{i}>0$ is the household's consumption, $\rho$ is the subjective discount rate, and $\mathbb{1}_{e}^{i}$ is an indicator function that takes the value of 1 if household $i$ is employed and 0 otherwise. When employed, households experience a disutility from the number of hours worked, $\omega \frac{\ell_{t}^{1+\psi}}{1+\psi}$, where $\psi$ is the inverse of the Frisch elasticity and $\omega$ a disutility parameter. When unemployed, they incur a non-pecuniary cost of unemployment, $\Phi=\omega \frac{\ell^{1+\psi}}{1+\psi}$, that corresponds to the steady-state disutility from hours worked. ${ }^{7}$ The budget constraint of household $i$ writes

$$
a_{t}^{i}+c_{t}^{i}=\left(1+r_{t-1}\right) a_{t-1}^{i}+\left(1-\tau_{t}\right)\left(\mathbb{1}_{e}^{i} w_{t} \ell_{t}+\left(1-\mathbb{1}_{e}^{i}\right) h \bar{w}\right)+\mathbb{1}_{e}^{i}\left(\Pi_{t}^{i}-T_{t}^{i}\right)
$$

where $a_{t}^{i}>0$ is the household's aggregate wealth and $r_{t-1}$ the risk-free return on government bonds between periods $t-1$ and $t$. When employed, household $i$ works $\ell_{t}$ hours paid at the hourly real wage $w_{t}$, and receives $\Pi_{t}^{i}-T_{t}^{i}$, with $\Pi_{t}^{i}$ being per capita total profits from firms and $T_{t}^{i}$ a per capita lump-sum tax. Hours worked and the real wage are taken as given by households; their determination is discussed in the following sub-section. When unemployed, household $i$ receives

\footnotetext{
${ }^{7}$ This assumption follows McKay and Reis (2016) and allows to trace the difference between the steady-state net values of being employed and unemployed only to the difference in the consumption levels associated with these two labor-market statuses.
} 
unemployment benefits $h \bar{w}$, where $h$ is the replacement rate and $\bar{w}$ denotes the steady-state real wage. Labor income and unemployment benefits are taxed at the same rate, $\tau_{t}$.

We assume that the number of matches in the economy is determined randomly by the following matching function:

$$
m_{t}=\chi \frac{u_{t} v_{t}}{\left(u_{t}^{\alpha}+v_{t}^{\alpha}\right)^{\frac{1}{\alpha}}},
$$

where $v_{t}$ is the number of vacancies posted by firms, $\chi>0$ is the matching-efficiency parameter, and $\alpha>0$ is the matching-curvature parameter, which governs the elasticity of substitution between unemployment and vacancies (given by $\frac{1}{1+\alpha}$ ). From the perspective of households, the probabilities of changing employment status are the separation rate, $s$ (constant and exogenous), when employed, and the time-varying job-finding probability, $f_{t} \equiv m_{t} / u_{t}$, when unemployed. Defining $\theta_{t} \equiv v_{t} / u_{t}$ as labor-market tightness, the job-finding probability is $f_{t}=\chi\left(1+\theta_{t}^{-\alpha}\right)^{-\frac{1}{\alpha}}$. As one can easily see, $f_{t}$ is an increasing and concave function of $\theta_{t}$, with a curvature that depends on $\alpha$. The concavity of $f_{t}$ captures the degree of matching frictions, which are minimized when $\alpha \rightarrow 0$ (in which case $f_{t}$ becomes linear in $\theta_{t}$ ). From the employers' perspective, the worker-finding (or vacancy-filling) probability is $q_{t} \equiv m_{t} / v_{t}=\chi\left(1+\theta_{t}^{\alpha}\right)^{-\frac{1}{\alpha}}$. The value of household $i$ is therefore given by

$$
\begin{aligned}
W\left(a_{t}^{i}, \mathcal{E}_{t}^{i}\right)=\max _{\left\{c_{t}^{i}, a_{t}^{i}\right\}} & \mathbb{E}_{t}\left\{\sum_{s=t}^{\infty}\left(\frac{1}{1+\rho}\right)^{s-t}\left(\log \left(c_{s}^{i}\right)-\mathbb{1}_{e}^{i} \omega \frac{\ell_{t}^{1+\psi}}{1+\psi}-\left(1-\mathbb{1}_{e}^{i}\right) \Phi\right)\right\} \\
\text { s.t. } \quad & a_{t}^{i}+c_{t}^{i}=\left(1+r_{t-1}\right) a_{t-1}^{i}+\left(1-\tau_{t}\right)\left(\mathbb{1}_{e}^{i} w_{t} \ell_{t}+\left(1-\mathbb{1}_{e}^{i}\right) h \bar{w}\right)+\mathbb{1}_{e}^{i}\left(\Pi_{t}^{i}-T_{t}^{i}\right), \\
& a_{t}^{i}>0, \\
& \operatorname{Pr}\left(\mathcal{E}_{t+1}^{i} \mid \mathcal{E}_{t}^{i}\right) \equiv \Lambda_{t}=\left[\begin{array}{cc}
1-s & s \\
f_{t} & 1-f_{t}
\end{array}\right] .
\end{aligned}
$$

\section{$2.2 \quad$ Firms}

The final (consumption) good is produced using differentiated varieties sold by monopolistically competitive retailers. Varieties are produced using an intermediate good, which is itself produced by firms using labor. For simplicity, and without loss of generality, we assume that each firm in the intermediate-good sector is a job.

Intermediate-good producers. Firms in the intermediate-good sector post vacancies, out of which a fraction $q_{t}$ will be filled in period $t$, accruing the total number of employed households. The cost of posting a vacancy is denoted by $\xi$. The intermediate good is produced using the following technology:

$$
y_{t}^{m}=z_{t} \ell_{t}
$$

where $z_{t}$ denotes productivity, and is sold to retailers at the (real) price $p_{t}^{m}$. The marginal value of 
a filled position is ${ }^{8}$

$$
J_{t}=p_{t}^{m} z_{t} \ell_{t}-w_{t} \ell_{t}+\mathbb{E}_{t}\left\{\frac{1}{1+r_{t}}\left((1-s) J_{t+1}+s V_{t+1}\right)\right\}
$$

where $p_{t}^{m} z_{t} \ell_{t}$ is the gross contribution of the marginal worker (i.e., her marginal product), and $w_{t} \ell_{t}$ her wage bill. The continuation value depends on the separation rate $s$ and the expected value of a vacancy. The latter is given by

$$
V_{t}=-\xi+\mathbb{E}_{t}\left\{\frac{1}{1+r_{t}}\left(\left(1-q_{t}\right) V_{t}+q_{t} J_{t+1}\right)\right\}
$$

The free entry condition $V_{t}=0$ holds, which implies that $\mathbb{E}_{t}\left\{\frac{q_{t} J_{t+1}}{1+r_{t}}\right\}=\xi$. The aggregate profits (net of vacancy-posting costs) made by intermediate-good producers are

$$
\Pi_{t}^{m}=\left(1-u_{t}\right)\left(p_{t}^{m} z_{t}-w_{t}\right) \ell_{t}-\xi v_{t} .
$$

As is well known, the equilibrium real wage in not uniquely determined in models with search and matching frictions, as there is a range of wages that firm are willing to pay and workers are willing to accept. Following Blanchard and Galí (2010), we assume that the real wage is determined according to the following rule:

$$
w_{t}=\bar{w} z_{t}^{\eta}
$$

where $\eta \in[0,1]$ is a parameter. Whenever $\eta$ is strictly less than 1 , the rule above implies that the difference between the marginal product of labor and the real wage is large when productivity is high, thus giving rise to real wage rigidity, the extent of which is inversely related to the value of $\eta .^{9}$

We also assume that workers are represented by a union that determines the amount of hours worked by each employed household by equating the marginal rate of substitution between the

\footnotetext{
${ }^{8}$ We assume that intermediate-good producers discount future marginal values of a filled position and of future vacancies at the equilibrium real interest rate $r_{t}$ and not at the subjective rate of the owners (employed households). Since the real interest rate is essentially driven by the saving behavior of firm owners, i.e., employed households, this approximation is innocuous.

${ }^{9}$ In a previous version of the paper, we also considered a wage-setting mechanism whereby the real wage is a linear combination of the steady-state wage and a newly bargained wage between employers and a union that represents workers (e.g., Krause and Lubik (2007) and Albertini and Fairise (2013)). The union negotiates based on the average value functions of employed and unemployed households, $W_{t}^{e}$ and $W_{t}^{u}$. The newly bargained wage, $w_{t}^{n}$, is determined as the solution to a Nash-bargaining problem that consists in maximizing a geometric average of the union surplus and the marginal value of a filled job

$$
w_{t}=\arg \max \left(W_{t}^{e}-W_{t}^{u}\right)^{\beta} J_{t}^{1-\beta}
$$

where $\beta$ is the bargaining power of the union/workers. To the extent that the wage equation exhibits sufficiently high inertia, results based on this alternative wage-setting mechanism are very similar to the ones reported in this paper, and are available upon request.
} 
average consumption of employed agents, $c_{t}^{e}$, and their hours worked to the after-tax real wage

$$
\omega \ell_{t}^{\psi} c_{t}^{e}=\left(1-\tau_{t}\right) w_{t}
$$

Retailers. There is a continuum of monopolistically competitive retailers indexed by $k \in[0,1]$, each of which produces a single differentiated variety using the intermediate good as input. The production function of retailer $k$ is given by

$$
y_{t}(k)=x_{t}^{m}(k)
$$

where $x_{t}^{m}(k)$ is the quantity of the intermediate input used by retailer $k$. The differentiated varieties are sold to a representative assembler that aggregates them into a final good. Let $P_{t}(k)$ denote the nominal price set by retailer $k$ for its variety. Demand for this variety by the final-good producer is given by $y_{t}^{d}(k)=\left(P_{t}(k) / P_{t}\right)^{-\varepsilon} y_{t}$, with $\varepsilon>1$ denoting the elasticity of substitution between varieties, and $y_{t}$ denoting total demand for the final good. Adjusting prices by the retailers entails Rotemberg-type price-adjustment costs. Let $P_{t}(k)$ denote the nominal price set by retailer $k$, the latter maximizes the discounted sum of its expected dividends, given by ${ }^{10}$

$$
\mathbb{E}_{t}\left\{\sum_{s=t}^{\infty}\left(\frac{1}{1+r_{s-1}}\right)^{s-t} \Pi_{s}^{r}(k)\right\}
$$

where

$$
\Pi_{t}^{r}(k)=\left[\frac{P_{t}(k)}{P_{t}}-p_{t}^{m}-\frac{\varphi}{2}\left(\frac{P_{t}(k)}{P_{t-1}(k)}-1\right)^{2}\right] y_{t}^{d}(k) .
$$

Assuming symmetry across retailers $\left(P_{t}(k)=P_{t}\right.$ and $\left.y_{t}^{d}(k)=y_{t}\right)$, their optimal pricing condition is given by

$$
\varepsilon-1=\varepsilon p_{t}^{m}-\varphi\left[\pi_{t}\left(1+\pi_{t}\right)-\mathbb{E}_{t}\left(\frac{\pi_{t+1}\left(1+\pi_{t+1}\right) y_{t+1}}{\left(1+r_{t}\right) y_{t}}\right)\right],
$$

where $\pi_{t}=P_{t} / P_{t-1}-1$ is the inflation rate. Notice that $p^{m}=(\varepsilon-1) / \varepsilon$ in the steady state, implying that monopolistic competition distorts the production of intermediate goods.

Finally, since $y_{t}=x_{t}^{m}=\left(1-u_{t}\right) y_{t}^{m}$, total profits are given by

$$
\Pi_{t}=\Pi_{t}^{m}+\Pi_{t}^{r}=\left(1-u_{t}\right)\left[\left(1-\frac{\varphi}{2} \pi_{t}^{2}\right) z_{t} \ell_{t}-w_{t} \ell_{t}\right]-\xi v_{t}
$$

and are fully redistributed to employed households so that $\Pi_{t}^{i}=\Pi_{t} /\left(1-u_{t}\right)$.

\footnotetext{
${ }^{10}$ Future profits are also discounted using the equilibrium real rate. See Footnote 8.
} 


\subsection{Government, aggregation, and equilibrium}

The government purchases public goods, $g_{t}$, and provides after-tax unemployment insurance to unemployed households. It finances this stream of expenditure by issuing one-period bonds and by levying lump-sum and labor-income taxes on employed households. We assume that the laborincome tax is constant, $\tau_{t}=\tau$. The government budget constraint, expressed in real terms, is therefore given by

$$
b_{t}=\left(1+r_{t-1}\right) b_{t-1}+g_{t}+(1-\tau) u_{t} h \bar{w}-\tau\left(1-u_{t}\right) w_{t} \ell_{t}-T_{t}
$$

where

$$
T_{t}=\left(1-u_{t}\right) T_{t}^{e}
$$

with $T_{t}^{e}$ denoting the per capita lump-sum tax paid by each employed household. In addition, we assume that lump-sum taxes evolve according to

$$
T_{t}=d_{T}\left(b_{t}-\bar{b}\right)
$$

where $\bar{b}$ denotes the steady-state level of debt, and $d_{T}>0$ is the tax-feedback parameter.

The central bank sets the nominal interest rate, $i_{t}$, according to the following simple rule:

$$
i_{t}=\bar{r}+\bar{\pi}+d_{\pi}\left(\pi_{t}-\bar{\pi}\right)
$$

where $\bar{r}$ and $\bar{\pi}$ are the steady-state interest and inflation rates, respectively, and $d_{\pi}>1$.

The market clearing conditions on the bonds and goods markets are, respectively

$$
\begin{aligned}
b_{t} & =\sum_{i} \Omega_{t}^{e, i} a_{t}^{i}+\sum_{i} \Omega_{t}^{u, i} a_{t}^{i} \\
y_{t} & =\left(1-u_{t}\right) z_{t} \ell_{t}\left(1-\frac{\varphi}{2} \pi_{t}^{2}\right)-\xi v_{t} \\
& =\sum_{i} \Omega_{t}^{e, i} c_{t}^{e, i}+\sum_{i} \Omega_{t}^{u, i} c_{t}^{u, i}+g_{t} .
\end{aligned}
$$

where $\Omega_{t}^{e, i}$ and $\Omega_{t}^{u, i}$ are the time-varying distributions of, respectively, employed and unemployed households over assets, and $c_{t}^{e, i}$ and $c_{t}^{u, i}$ denote their respective consumption functions defined over assets. Notice that our measure of aggregate output, $y_{t}$, is net of price-adjustment and vacancy costs. Due to Walras' law, the last equilibrium condition is redundant. 


\subsection{Shocks}

The economy is driven by two exogenous disturbances, public spending and productivity shocks, governed by the following $\mathrm{AR}(1)$ processes:

$$
\begin{aligned}
& \ln g_{t}=\left(1-\rho_{g}\right) \ln g+\rho_{g} \ln g_{t-1}+\epsilon_{t}^{g} \\
& \ln z_{t}=\left(1-\rho_{z}\right) \ln z+\rho_{z} \ln z_{t-1}+\epsilon_{t}^{z}
\end{aligned}
$$

where $0<\rho_{g}, \rho_{z}<1$, and $\epsilon_{t}^{g}$ and $\epsilon_{t}^{z}$ are serially and mutually uncorrelated innovations.

\subsection{Calibration}

The model is calibrated at a quarterly frequency. In what follows, we justify our chosen values for the model parameters, which are summarized in Table 1.

Preferences and production. We impose a subjective interest rate of $4 \%$ annually, implying $\rho=$ 0.01 , The equilibrium steady-state real interest rate, $\bar{r}$, is lower than the subjective rate due to precautionary saving, which is used by the households to self-ensure against unemployment risk. Our calibration implies a $3.69 \%$ annual real interest rate. We fix the Frisch elasticity of labor supply at $1 / \psi=1$ and adjust the labor-disutility parameter, $\omega$, to get $\ell=1$ in the steady state. Following Kaplan, Moll, and Violante (2018), we set the elasticity of substitution between the differentiated varieties to $\varepsilon=10$, implying a steady-state mark-up of $11.11 \%$. The price-adjustmentcost parameter is set to $\varphi=60$, a conventionally accepted value.

Labor market. We seek to replicate key characteristics of the European labor market. We set the matching-curvature parameter to $\alpha=1.25$ as in Petrosky-Nadeau and Zhang (2013). The quarterly separation rate is set to $s=0.025$, which is consistent with a monthly separation rate of $0.63 \%$, very close to the numbers reported by Elsby, Hobijn, and Şahin (2013) for Continental Europe. We target an unemployment rate of $8 \%$, in line with the average of natural unemployment rates in European countries over the last few years. Given the value of the separation rate, this target is consistent with a steady-state quarterly job-finding probability of 0.2875 , or 0.08125 on a monthly basis, close to the numbers found by Elsby, Hobijn, and Şahin (2013). ${ }^{11}$ We set the worker-finding probability to $q=0.7$ following den Haan, Ramey, and Watson (2000) and Ravenna and Walsh (2008). Accordingly, the matching-efficiency parameter is set to $\chi=0.8787$. To determine the steady-state real wage, $\bar{w}$, we assume that it solves a Nash bargaining problem between employers and a union that represents workers and that negotiates based on the average value functions of employed and unemployed agents (see Footnote 9). The union's bargaining power is calibrated to $\beta=0.75$. The baseline replacement rate is set to $h=0.6$, in line with the relatively high replacement

\footnotetext{
${ }^{11}$ These transition probabilities are almost exactly those reported for France.
} 
rates prevailing in European countries (see, for instance, Esser, Ferrarini, Nelson, Palme, and Sjüberg (2013)). Conditional on the values of the remaining parameters, this replacement rate yields a unit vacancy cost of $\xi=0.4524 \bar{w}$. Although the cost per vacancy is somewhat larger than what Hagedorn and Manovskii (2008) suggest for the U.S., the total steady-state vacancy costs, $\xi \bar{w} v$, represent $1.44 \%$ of GDP, which remains within the range of values used in the literature. Given the chosen parameter values, we obtain $\bar{w}=0.8797$. Finally, following Gornemann, Kuester, and Nakajima (2016), we set the elasticity $\eta$ to 0.45 .

Government, central bank and shocks. We set the government spending to GDP ratio to $g / y=0.2$, and adjust the labor-income tax rate to match a $60 \%$ steady-state debt-output ratio $(b /(4 y)=0.6)$, which implies $\tau=0.2891$. The tax-rule feedback parameter is set to a rather low value - yet sufficiently high to induce stable debt dynamics $-d_{T}=0.1$. The steady-state inflation rate, $\bar{\pi}$, is assumed to be equal to 0 , and the monetary policy rule parameter is set to $d_{\pi}=1.5$. Finally, the autocorrelation coefficients are set to $\rho_{g}=0.8$ for government spending shocks and $\rho_{z}=0.9$ for productivity shocks.

Table 1: Parameter values

\begin{tabular}{lr}
\hline \hline Subjective interest rate & $\rho=0.01$ \\
Steady-state quarterly real interest rate & $r=0.9116 \%$ \\
Frisch elasticity of labor supply & $1 / \psi=1$ \\
Labor disutility parameter & $\omega$ adjusted to get $\ell=1$ \\
Steady-state mark-up & $(\varepsilon-1)^{-1}=0.1111$ \\
Rotemberg price adjustment cost & $\varphi=60$ \\
Separation rate & $s=0.025$ \\
Job-finding rate & $f=0.2875$ \\
Worker-finding rate & $q=0.7$ \\
Matching curvature & $\alpha=1.25$ \\
Wage elasticity w.r.t to labor productivity & $\eta=0.45$ \\
Matching efficiency & $\chi=0.8787$ \\
Unit vacancy posting cost & $\xi=0.4524 \bar{w}$ \\
Replacement rate & $h=0.6$ \\
Labor income tax rate & $\tau=0.2891$ \\
Government spending in GDP & $g / y=0.2$ \\
Debt to annual GDP ratio & $b /(4 y)=0.6$ \\
Tax rule feedback parameter & $d_{T}=0.1$ \\
Steady-state inflation rate & $\bar{\pi}=0$ \\
Monetary policy rule parameter & $d_{\pi}=1.5$ \\
Persistence of government spending shocks & $\rho_{g}=0.8$ \\
Persistence of productivity shocks & $\rho_{z}=0.9$ \\
\hline
\end{tabular}




\subsection{Solution method}

The model is solved in two separate steps. The first step solves the steady state, including the stationary distribution of asset holdings and the policy functions over an asset grid. The second step solves the transition dynamics after stationary shocks around the steady state using a non-linear algorithm. The details of both steps are given in the Appendix but the main idea is to rewrite the optimizing conditions (in particular, the value functions of households) in continuous time to solve the corresponding Hamilton-Jacobi-Bellman equation that describes the households' problem for a given level (for the steady state) or path (for the transition dynamics) of the real interest rate and of the tightness ratio over a given asset grid. Once asset holdings and policy functions are derived, solving the Kolmogorov forward equation gives the corresponding distribution of households over the asset grid. We use 250 grid points and a linear grid. Taking advantage of the continuous-time formulation of the problem is in direct relation with the recent breakthrough in heterogeneous-agent models exemplified by the work of Kaplan, Moll, and Violante (2018).

\section{7 $\quad$ Steady-state distributions, policy functions and MPCs}

Figure 1 plots the steady-state distributions and policy functions over the asset grid. It shows that the worker's value function is increasing in the level of asset holdings regardless of her employment status, and that, as expected, the value of being unemployed is always below the value of being employed. The consumption functions are increasing in the level of assets held, but more strongly so for low levels of assets, especially for unemployed households.

Saving is positive for employed households, which reflects the precautionary motive, especially at low levels of assets. When holding more assets, employed households save relatively less because their asset level already provides insurance against potential unemployment spells. Unemployed households, on the contrary, always feature negative saving: consumption smoothing when unemployed requires using savings to sustain consumption. The size of this consumption-smoothing motive increases with the level of assets: unemployed households holding more assets were previously employed and quite wealthy, and used them to sustain large levels of consumption, which they want to preserve as much as possible when unemployed. This explains why unemployed households have large negative savings at high levels of assets.

The marginal distributions of employed and unemployed households on the asset grid show that most employed households are willing to hold large levels of assets to self-insure against unemployment risk. In addition, unemployed households that experience long unemployment spells become constrained and end up holding zero assets. Their proportion amounts to $6 \%$ of unemployed households, which is not surprising given the transition matrix featuring a relatively low job-finding probability. 
Figure 1: Steady-state distributions and policy functions.
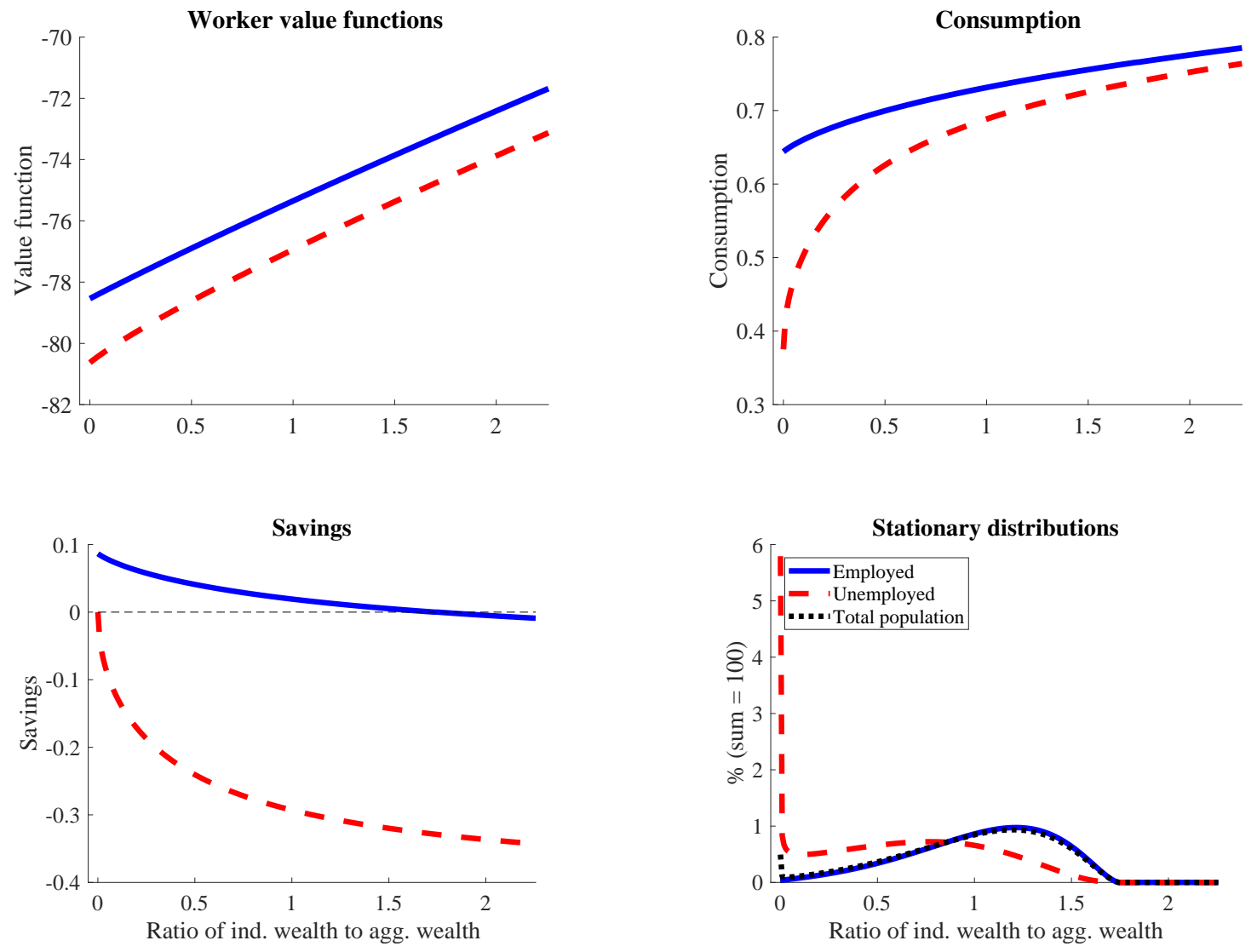
What does our model predict in terms of marginal propensities to consume (MPCs)? To answer this question, we carry out the following experiment. We feed the model with an exogenous lumpsum transfer that is distributed equally across all households, and we compute the change in the current consumption of each household. The transfer has a half-life of 6.5 quarters and - given the low value of $d_{T}$ - is financed mostly by public debt in the first periods and eventually by an increase in the lump-sum taxes levied on employed households later on. This financing scheme ensures that all households experience an increase in their current income, thus allowing for a comprehensive comparison of the impact MPCs across households.

The left panel of Figure 2 reports the impact MPCs of employed and unemployed households for different ratios of individual to aggregate wealth. Two main observations stand out. First, the impact MPC decreases with (relative) wealth, regardless of households' employment status. Second, it is larger for unemployed households at any level of asset holdings, consistently with the empirical regularity reported by Carroll, Slacalek, and Tokuoka (2014), and is equal to 1 for unemployed households holding zero assets. This differential consumption response between employed and unemployed households will be at the heart of the mechanism underlying the results presented in the following sections. Using the stationary distribution of households, one can also generate the distribution of aggregate MPCs in our economy, which is shown in the right panel of Figure 2. Aggregate MPCs are slightly larger than 0.5 for the lowest percentiles, around 0.15 at the $10^{\text {th }}$ percentile, and below 0.1 at the $20^{\text {th }}$ percentile. By and large, our model is capable of replicating the pattern of the distribution of aggregate MPCs observed in the data, at least qualitatively. $^{12}$ Interestingly, we obtain a very similar distribution of aggregate MPCs to that reported by Luetticke (2019) without having to rely on participation shocks to generate a large fraction of wealthy hand-to-mouth households. ${ }^{13}$

\section{Unconditional Effects of Government Spending Shocks}

We start by discussing the effects of an increase in public spending occurring while the economy is initially in the steady state. We first present the results based on the benchmark model described above before turning to counterfactual economies in which some of our modeling assumptions are relaxed one at a time. The dynamic effects of a government spending shock are illustrated by means of impulse response functions. Following common practice in the literature, we quantify the effects

\footnotetext{
${ }^{12}$ Quantitatively, the mean aggregate impact MPC implied by the model (0.05) is smaller than that observed in the data (between 0.08 and 0.5 according to various empirical studies). In the Appendix, we provide an extended version of the model that replicates the observed empirical distributions of asset holdings and Gini coefficient on liquid wealth. The extended model embeds the same features that drive the results in the stripped-down version presented in Section 2.

${ }^{13}$ Using a model that shares several features with ours, Daeha (2020) disentangles the roles of precautionary saving and MPC heterogeneity in amplifying output volatility relative to a representative-agent model. He finds that the bulk of amplification is driven by heterogeneity in MPC.
} 
Figure 2: MPCs out of a transfer shock.
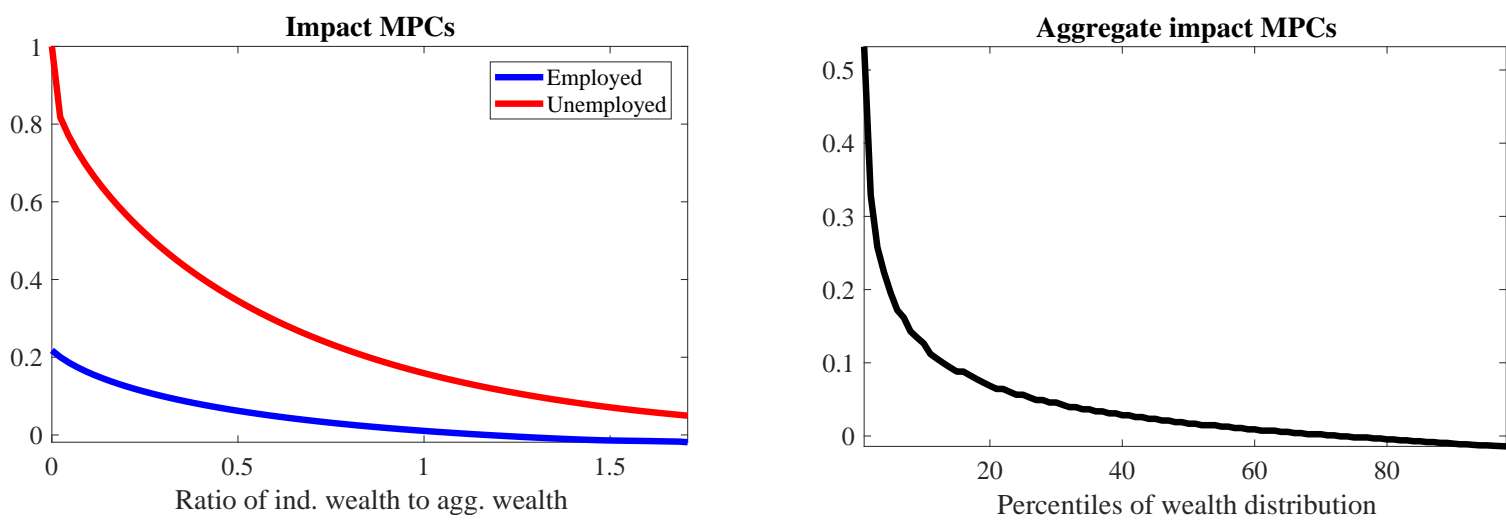

of the spending shock using the present-value multiplier, defined as the expected discounted sum of the changes in a generic variable $x_{t}$ up to a given horizon, $\mathcal{H}$, divided by the expected discounted sum of changes in government spending over the same horizon

$$
\mathcal{M}(\mathcal{H})=\frac{\mathbb{E}_{t} \sum_{j=0}^{\mathcal{H}} \prod_{i=0}^{j}\left(1+r_{t+i}\right)^{-1}\left(x_{t+j}-x\right)}{\mathbb{E}_{t} \sum_{j=0}^{\mathcal{H}} \prod_{i=0}^{j}\left(1+r_{t+i}\right)^{-1}\left(g_{t+j}-g\right)},
$$

where $r_{t}$ is the time-varying real interest rate implied by the model. Throughout the paper, we focus on $\mathcal{M}(\mathcal{H} \rightarrow \infty)$. The present-value output multiplier is reported in Table 2 .

\subsection{Benchmark economy}

Figure 3 depicts the impulse responses of key variables to a $1 \%$ increase in government spending relative to its steady-state level. The shock increases aggregate demand in the economy, thus raising demand for intermediate goods. Whether intermediate-good producers respond by posting more vacancies to meet the additional demand depends on whether the marginal value of a filled position, $J_{t}$, increases. As can be seen by iterating Equation (5) forward (and noting that $V_{t}=0$ in equilibrium), the response of $J_{t}$ is driven by two effects: the change in employers' current and future profits, and the change in the rate at which future profits are discounted.

Price rigidity in the retail sector implies that the retailers' real marginal cost (or, equivalently, the real price of intermediate goods, $p_{t}^{m}$ ) increases persistently in response to the shock. ${ }^{14}$ To the extent that hours worked increase (which they do in equilibrium, as we explain below) and since the real wage remains constant, intermediate-good producers' period-by-period profits will also increase

\footnotetext{
${ }^{14}$ In fact, the increase in $p_{t}^{m}$ occurs with a delay of a few quarters and not immediately after the shock. This is due to the hump-shaped response of aggregate inflation (see Equation 14), which in turn reflects the non-monotonic response of aggregate consumption (discussed below).
} 
persistently. ${ }^{15}$ We refer to this channel as the undiscounted-profit effect. At the same time, the increase in aggregate demand raises the real interest rate, thus lowering the present discounted value of future profits, ceteris paribus. We dub this channel the discounting effect. In our economy, the undiscounted-profit effect dominates the discounting effect, such that the marginal value of a filled position rises in response to the increase in public spending, inducing firms to post more vacancies. The resulting increase in labor-market tightness raises the job-finding probability, boosting hiring and driving unemployment down in a persistent manner. These predictions are consistent with the empirical evidence on the labor-market effects of government spending shocks, documented, for instance, by Monacelli, Perotti, and Trigari (2010).

Figure 3: Impulse responses to a $1 \%$ government spending shock around the steady state.

(a) Output

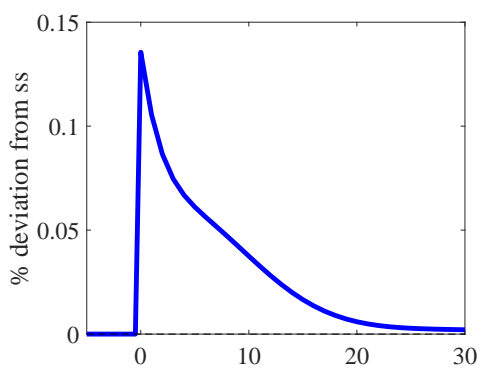

(d) Aggregate consumption

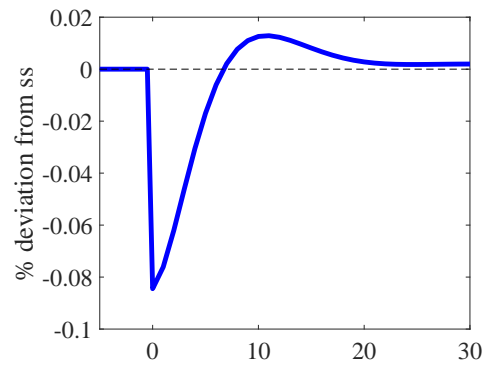

(g) Job finding probability

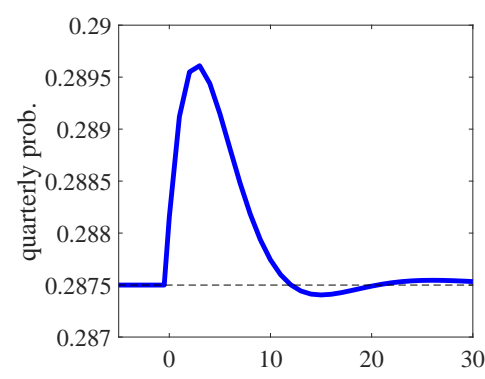

(b) Hours worked

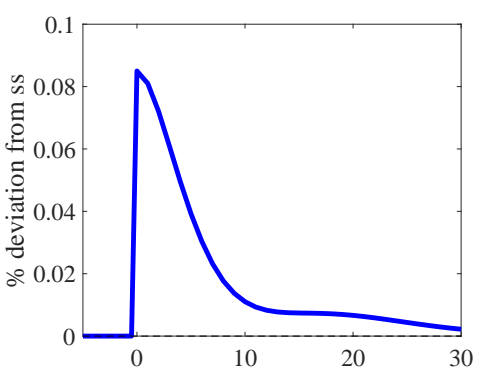

(e) Consumption (empl.)

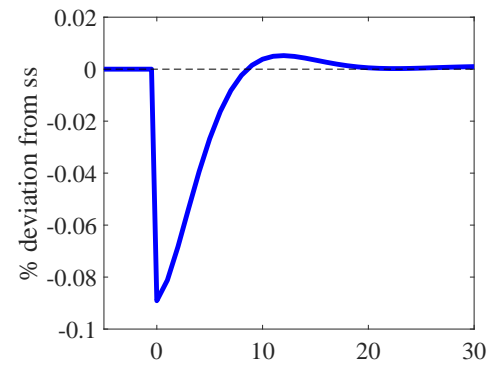

(h) Real interest rate

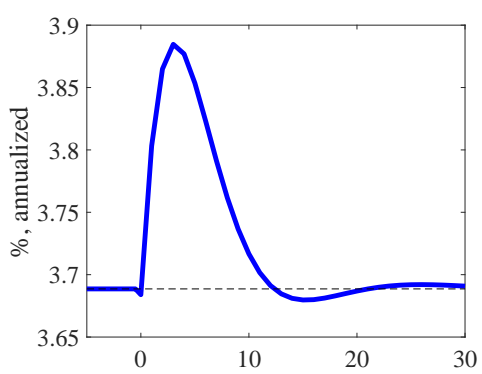

(c) Unemployment

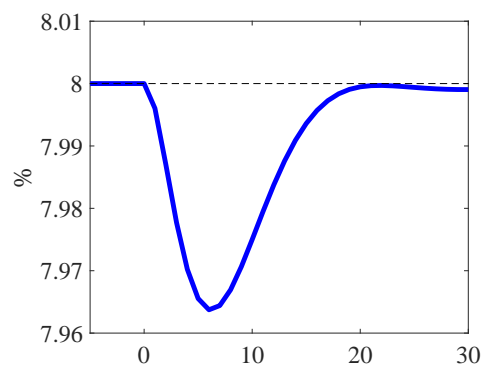

(f) Consumption (unempl.)

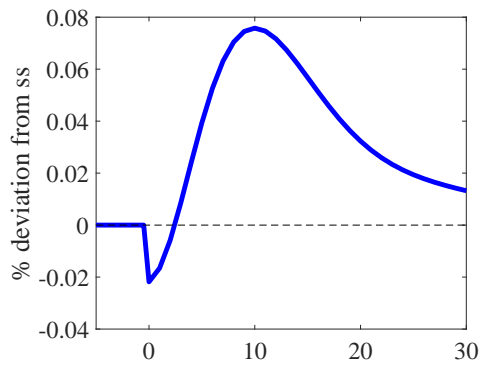

(i) Debt to GDP

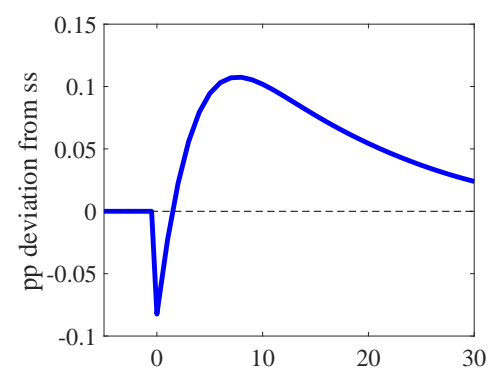

The increase in public spending gives rise to a negative wealth effect for employed households

\footnotetext{
${ }^{15}$ This result still holds when we assume that the real wage is governed by a Nash-bargaining mechanism, such as that described in Footnote 9. In this case, the real wage rises in response to the government spending shock, but does so to a much lesser extent than does the real price of intermediate goods.
} 
- due to the implied hike in future taxes needed to finance the fiscal expansion - leading them to cut their consumption. This crowding-out, however, is mitigated by the fall in precautionary saving triggered by the reduction in unemployment risk. The negative wealth effect also leads the union to raise the supply of hours. Since the real price of intermediate goods rises while the real wage remains constant, the increase in labor along the intensive margin amplifies the increase in the marginal value of a filled position. The per capita consumption of unemployed households initially falls, but to a much lesser extent than that of employed households. It then increases significantly and persistently, converging to its steady-state level from above. This (delayed) crowding-in is explained by the increase in the job-finding probability, which shortens the expected duration of unemployment spells and induces unemployed households to use their precautionary saving to consume more. This effect is only marginally mitigated by the expected increase in the tax burden of unemployed households as they anticipate to start contributing to the financing of government purchases as soon as they change status and become employed.

Aggregate output is defined as the sum of aggregate consumption and government spending. For a given level of public spending, the output response to shocks is therefore larger the larger the response of aggregate consumption. In our economy, two interconnected mechanisms contribute to amplifying the response of aggregate consumption to shocks: the precautionary motive and the composition effect. By reducing unemployment, higher government spending mitigates unemployment risk - thus reducing precautionary saving, which in turn fuels the increase in aggregate demand - and raises the fraction of employed households, who consume more on average than unemployed households. The conjunction of these two channels yields a spending multiplier of 0.86 , as reported in the first line of Table 2. This value lies well within the range of empirical estimates reported in the literature (see Ramey (2019) for a recent overview).

Table 2: Unconditional output multipliers.

\begin{tabular}{lc}
\hline \hline & $\begin{array}{c}\text { Present-value } \\
\text { multiplier }\end{array}$ \\
\hline Benchmark economy & 0.8603 \\
Variants & \\
$\quad$ No composition effect & 0.8246 \\
Complete markets & 0.6403 \\
No intensive margin & 0.3268 \\
Flexible prices & 0.6843 \\
Tax financing & 0.7223 \\
\hline
\end{tabular}

Note: The unconditional multipliers are derived by assuming that the economy is initially in the steady state. 
The spending multiplier delivered by our model is significantly larger than the counterfactually low multipliers typically obtained in models with search and matching frictions but with perfect insurance (e.g., Monacelli, Perotti, and Trigari (2010)), or in models with incomplete insurance markets but with a frictionless labor market (e.g., Hagedorn, Manovskii, and Mitman (2019)). Monacelli, Perotti, and Trigari (2010) show that it is possible to increase the size of the multiplier in a standard model with search and matching by assuming large average steady-state values of non-work to work activities - the equivalent of the replacement rate, $h$, in our model. But even when this parameter is assumed to be very close to its upper limit of 1 , their model falls short of matching the spending multiplier estimated in the data. By contrast, our model generates an empirically plausible multiplier without relying on implausibly large values of the replacement rate.

\subsection{Counterfactual economies}

To shed light on the role of our assumptions in generating an empirically plausible multiplier, we study four counterfactual variants of the model. The dynamic responses of output and unemployment implied by these versions are shown in Figures 4 to 7 (where we superimpose on the counterfactual responses those obtained from the benchmark economy), and the corresponding present-value output multipliers are reported in Table 2.

Consider first an economy that is identical to our benchmark in every respect except for the way aggregate output is computed. The latter is evaluated using the steady-state fractions of employed and unemployed households, thus neutralizing the composition effect on aggregate consumption stemming from changes in the unemployment rate. ${ }^{16}$ The output multiplier obtained in this case (0.82) is only slightly smaller than that implied by benchmark economy, reflecting the fact that, in the neighborhood of the steady state, the unemployment rate falls by a few percentage points in response to the government spending shock. As we will show below, however, the contribution of the composition effect to the size of the output multiplier becomes significantly larger when government spending occurs during a downturn.

Next, consider an economy with complete insurance markets, that is, one in which a perfect risksharing mechanism exists whereby households enjoy the same level of consumption irrespective of their employment status. In this environment, household heterogeneity becomes irrelevant for the size of the output multiplier since both the precautionary-motive and composition-effect channels are inoperative, even if the unemployment rate varies. Figure (5) shows that the maximum fall in unemployment is of similar magnitude under complete and incomplete markets. In the former case, however, the unemployment rate reaches its trough during the period following the shock and returns to its steady-state level quite rapidly, mirroring the rapid adjustment of the job-

\footnotetext{
${ }^{16}$ It should be emphasized, however, that this experiment does not fully shut down the general-equilibrium effects of the change in the relative fraction of unemployed agents in total population. The experiment therefore underestimates the contribution of the composition channel to the output multiplier.
} 
Figure 4: Impulse responses to a $1 \%$ government spending shock: Benchmark vs. no composition effect.

(a) Output

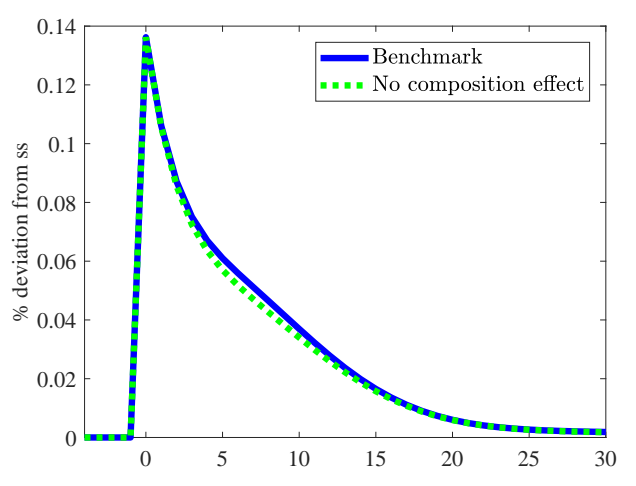

(b) Unemployment

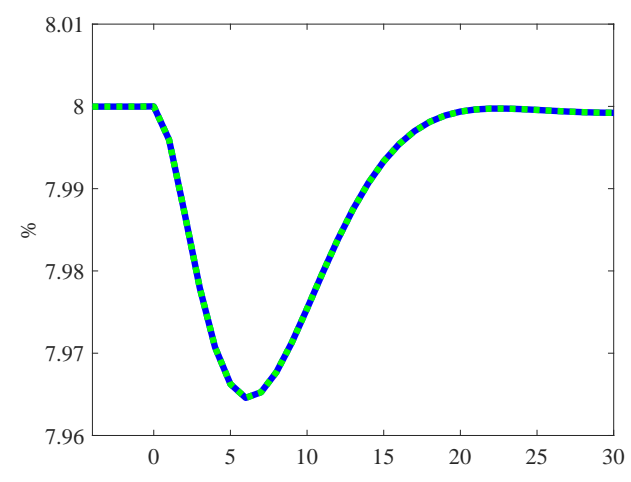

finding probability. This response contrasts with the protracted decline in the unemployment rate obtained under incomplete markets, which reflects the feedback loop between the reduction in unemployment risk and the increase in aggregate demand. Because unemployment risk and precautionary saving are absent under complete markets, consumption is more crowded out by the increase in public spending than in the benchmark economy. In this case, the multiplier is equal to 0.64 , suggesting that the government's ability to alleviate unemployment risk through higher public spending amplifies the present-value multiplier by roughly $35 \%$.

By inspecting Figure (5), one can see that output rises initially less in the benchmark economy than under complete markets, reflecting the fact that the intertemporal-substitution channel is weaker in the former case than in the latter (see Hagedorn, Manovskii, and Mitman (2019)). However, because the consumption adjustment is more gradual in the benchmark economy, it leads to a more persistent increase in aggregate demand and thus to a more persistent decline in unemployment, which in turn further mitigates the crowding-out of consumption (even leading to crowding-in) at longer horizons by reducing unemployment risk. As a result, the increase in aggregate output is more persistent in the benchmark economy than when markets are complete, thus accounting for the difference in the output multiplier across the two economies.

In the third variant, we shut down the intensive margin of labor adjustment, as in the vast majority of existing models of involuntary unemployment, such that as aggregate output can only increase through the entry of new firms - recall that each firm is a job. To do so, we assume that hours worked remain equal to their steady-state level in response to shocks. Because the adjustment of hours worked is inhibited, the undiscounted-profit effect is smaller than in the benchmark economy, and is in fact dominated by the discounting effect at the time of the shock, leading to a temporary fall in the value of a filled a job and thus to a temporary increase in unemployment (see Figure 6). Eventually, unemployment declines under constant hours worked; however, this effect is largely dominated by the fact that the output of each intermediate-good producer is smaller than 
Figure 5: Impulse responses to a $1 \%$ government spending shock: Benchmark vs. complete markets.

(a) Output

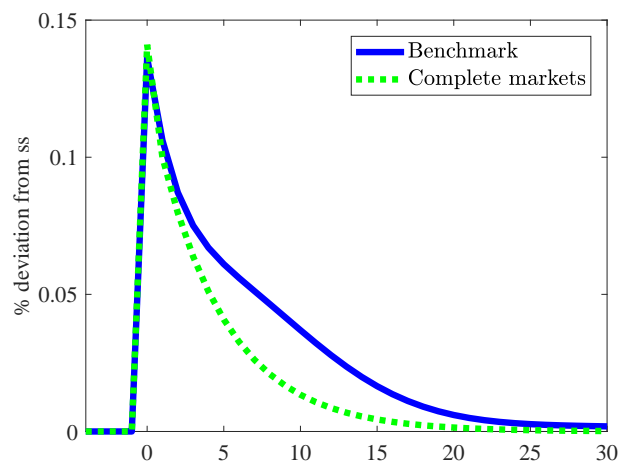

(b) Unemployment

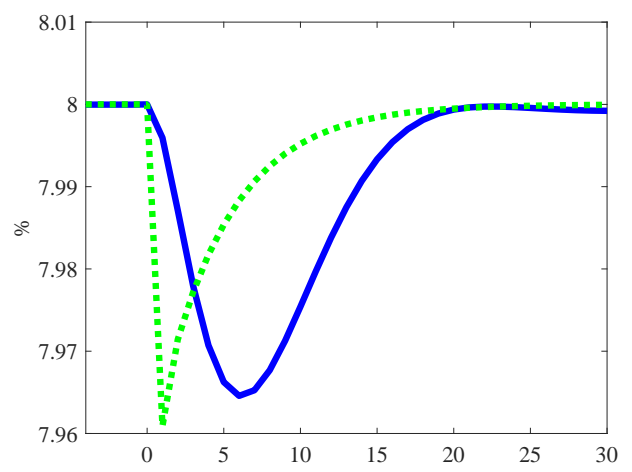

in the benchmark economy, leading to a much smaller output multiplier (0.33). ${ }^{17}$ This exercise highlights the critical importance of considering both the extensive and the intensive margins of labor adjustment to generate empirically plausible spending multipliers.

Figure 6: Impulse responses to a $1 \%$ government spending shock: Benchmark vs. no intensive margin.

(a) Output

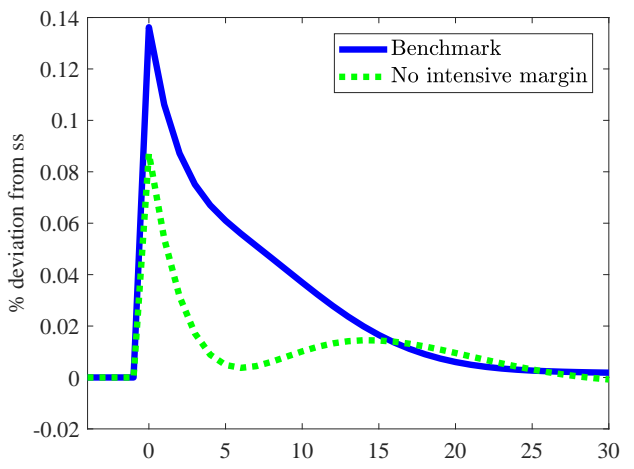

(b) Unemployment

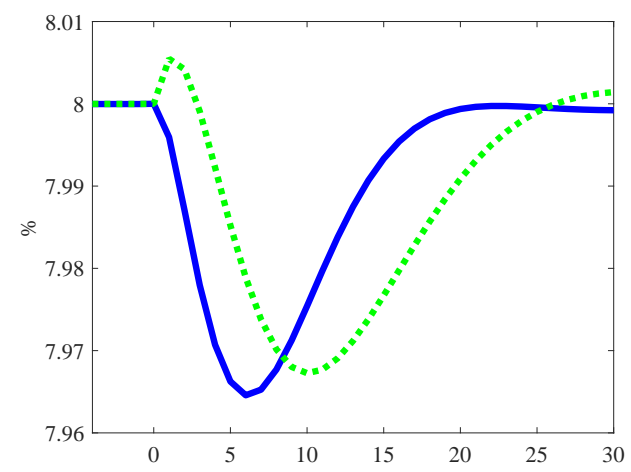

Finally, we abstract from price rigidity and assume instead that retailers set prices in a fully flexible manner. This leaves their real marginal cost - and thus the real price of intermediate goods — unchanged in response to the spending shock, implying $p_{t}^{m}=p^{m}$. Because the real wage also remains constant, current and future profits of intermediate-good producers do not change, which nullifies the undiscounted-profit effect. However, the discounting effect is still operative as the real interest rate rises, causing the marginal value of a filled position to fall. This leads to a decline in vacancies and in the job-finding probability. As a result, unemployment rises persistently in response to the increase in public spending, as opposed to the fall obtained under sticky prices (see Figure 7). The increase in unemployment risk triggers an increase in precautionary saving on the

\footnotetext{
${ }^{17}$ Output increases on impact despite the fact that employment is predetermined and hours worked are constant. This is due to the reduction in vacancy-posting and price-adjustment costs.
} 
part of employed and unemployed households, who cut their consumption by more than under rigid prices. Although the supply of hours worked increases more than in the benchmark economy, the net effect of the spending shock on aggregate output is smaller, producing a present-value output multiplier of 0.68 .

Figure 7: Impulse responses to a 1\% government spending shock: Benchmark vs. flexible prices.

(a) Output

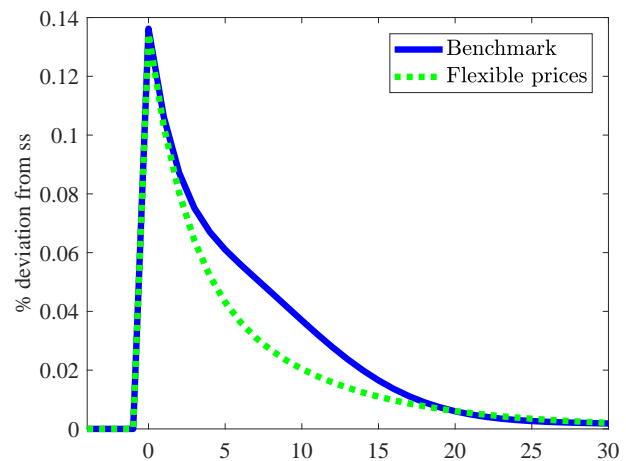

(b) Unemployment

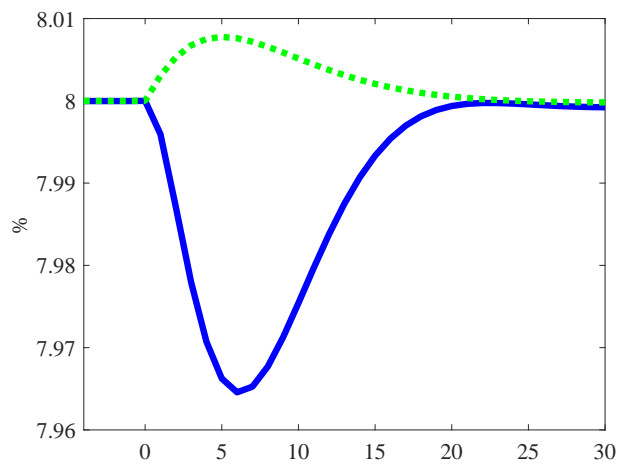

\subsection{Tax versus debt financing}

In the benchmark economy, the aggregate demand channel, through which government purchases of goods and services reduces unemployment risk and thus precautionary saving, is interwoven with the channel operating through the issuance of new government bonds. The latter affects the distribution of bond holdings by allowing households that would otherwise hold zero debt to become bond holders. To disentangle the two channels, we study a version of our economy in which the increase in public spending is entirely financed through lump-sum taxes, such that the stock of public debt remains constant at its steady-state level:

$$
b_{t}=\bar{b}
$$

When the increase in public spending is tax-financed, it tends to lower the current income of employed households, since taxes rise immediately rather than in the future as with the debtfinancing scheme of the benchmark model. ${ }^{18}$ Since Ricardian equivalence does not hold in our economy, this leads to a larger fall in the consumption of employed households, who bear the tax burden, and to a smaller increase in the consumption of unemployed households, who expect to pay their share of the tax hike once they find a job. The resulting output multiplier (of 0.72 , see Table 2) is lower than in the benchmark economy, but is still larger than in the complete-market economy.

\footnotetext{
${ }^{18}$ Strictly speaking, the increase in government spending in the benchmark economy is financed using a mix of debt and lump-sum taxes. Given the calibrated value of $d_{T}$, however, additional spending is mostly financed by debt.
} 


\section{State-Dependent Effects of Government Spending Shocks}

In this section, we study how the effects of an increase in government spending differ depending on whether the economy is in recession or expansion. We generate theses states by assuming that the economy is initially in the steady state when a productivity shock occurs. A negative shock will result in a recession whereas a positive shock will lead to an expansion. We start by discussing the dynamic effects of these shocks, before turning to those associated with an increase in government spending conditionally on the state of the economy.

\subsection{The economy's response to productivity shocks}

Figure 8 shows the economy's response to negative and positive shocks to labor productivity, $z_{t}$. The shocks are calibrated to $\pm 1 \%$. Consider first the negative shock. A fall in labor productivity lowers the marginal value of a filled position, inducing intermediate-good producers to post less vacancies, and lowering labor-market tightness and the job-finding probability. As a result, the number of successful matches falls and unemployment rises in equilibrium. At the peak, the unemployment rate surges by roughly 2 percentage points relative to its steady-state level. The magnitude of the unemployment response suggests that the model is capable of delivering sizable fluctuations in hiring activities in response to productivity shocks, a result that standard search and matching models typically fail to generate, as was first emphasized by Shimer (2005). Real wage rigidity enables the model to yield substantial variability in labor-market variables following a productivity shock without having to rely on extreme values of the replacement rate, as proposed by Hagedorn and Manovskii (2008).

The negative productivity shock lowers aggregate output, consumption, and the real wage, but raises the supply of hours worked. At the trough, aggregate output falls by approximately $1.3 \%$ relative to its steady-state level, which suggests that the scenario under consideration captures typical recessions experienced by actual economies. Again, the precautionary motive drives the dynamics of the (per capita) consumption of unemployed households: the perspective of longer unemployment spells leads them to consume much less and to save more. During the quarters following the shock, the fall in the consumption of unemployed households is more than twice larger than the fall in the consumption of employed households. The resulting decline in aggregate consumption is significantly larger than that predicted by a model with perfect insurance.

A positive productivity shock produces the opposite effects: output, consumption, the real wage, and posted vacancies rise, while hours worked and the unemployment rate both fall. Quantitatively, however, the effects of positive and negative productivity shocks are highly asymmetric: the expansion in economic activity resulting from the favorable shock is much less pronounced than the contraction caused by the (equal-size) adverse shock. For instance, while output falls by $1.3 \%$ 
Figure 8: Impulse responses to productivity shocks.

(a) Output

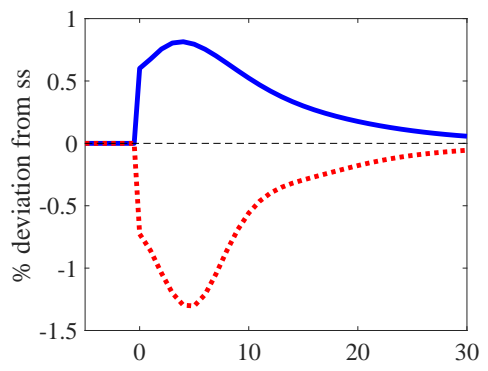

(d) Aggregate consumption

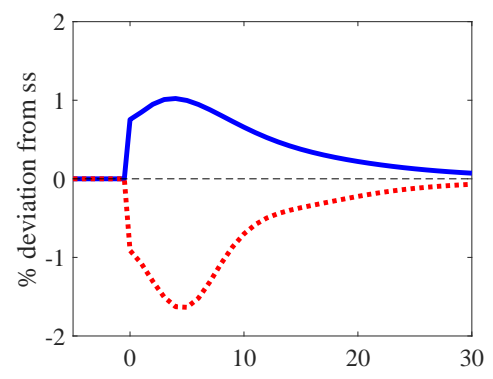

(g) Job finding probability

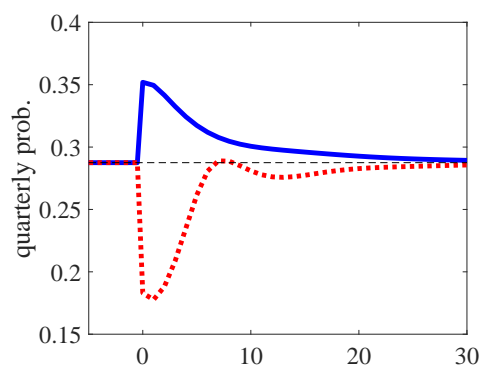

(b) Hours worked

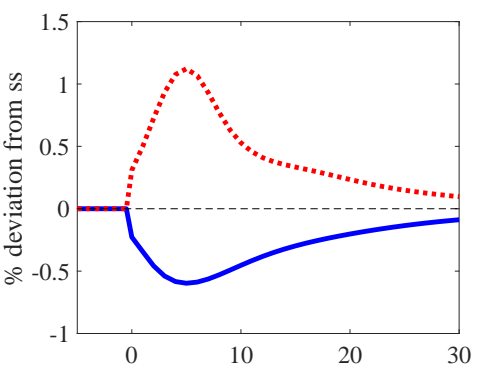

(e) Consumption (empl.)

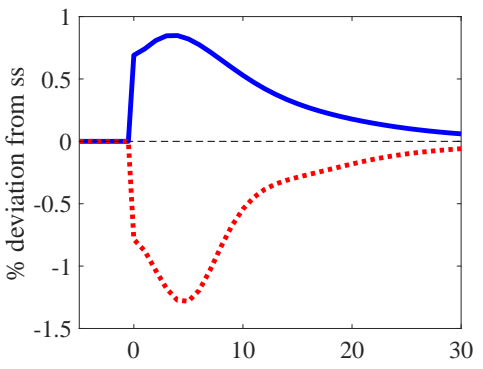

(h) Real interest rate

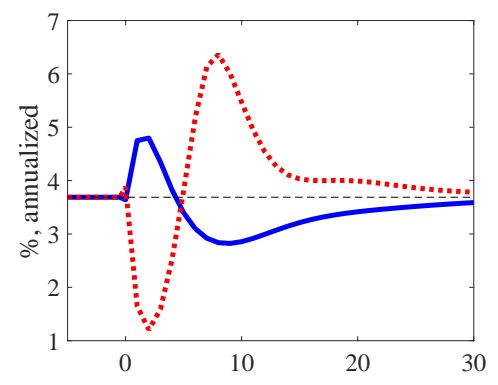

(c) Unemployment

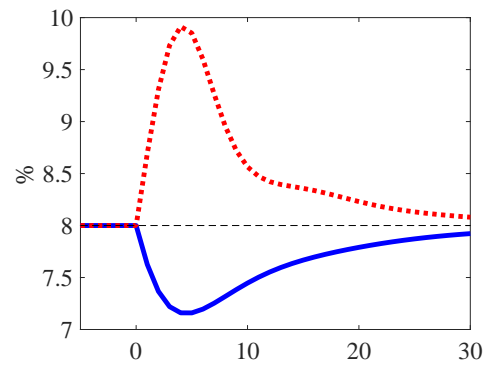

(f) Consumption (unempl.)

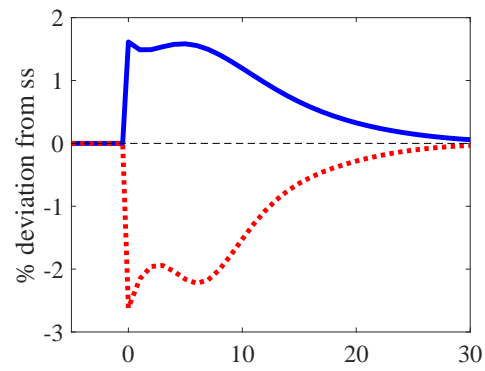

(i) Debt to GDP ratio

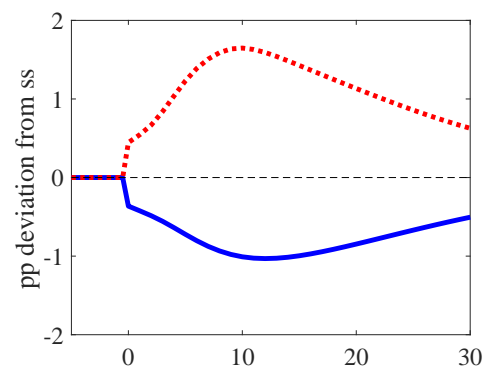

Solid blue: $1 \%$ positive shock. Dotted red: $1 \%$ negative shock. 
(at the trough) relative to its steady-state level in response to the negative productivity shock, it only rises by roughly $0.8 \%$ (at the peak) following the positive shock. The asymmetry is even more striking in the response of the unemployment rate, which increases by more than 1.9 percentage points (at the peak) in response to the negative productivity shock but falls by only 0.8 percentage points (at the peak) after the favorable shock. These predictions are consistent with the empirical observation that recessions are larger and more persistent than expansions (see, for example, Galí, Gertler, and López-Salido (2007) and Petrosky-Nadeau and Zhang (2013)).

The asymmetry (or sign dependence) in the effects of productivity shocks hinges on two generic properties of models with search and matching frictions in the labor market. First, the law of motion of unemployment implies that there is more job destruction when the job-finding probability falls than job creation when the job-finding probability increases by the same amount. ${ }^{19}$ Second, the concavity of the job-finding probability (and hence employment) with respect to labormarket tightness (recall that $\left.f_{t}=\chi\left(1+\theta_{t}^{-\alpha}\right)^{-\frac{1}{\alpha}}\right)$ signifies that unemployment falls less when the labor market tightens than it rises when the market becomes slack, for a given (absolute value of the) change in the degree of market tightness. ${ }^{20}$ Under incomplete insurance markets, these two properties imply that precautionary saving and the fraction of low-consumption agents in total population decline more following an adverse shock than they rise following a favorable shock of the same size, further exacerbating the asymmetry in the economy's response to positive and negative productivity shocks.

\subsection{The effects of government spending in recessions and expansions}

We now study the state dependence of the effects of government spending. For this purpose, we perform the following experiment. We first consider a baseline scenario in which only a productivity shock hits the economy. Then, we consider an alternative scenario in which the economy is simultaneously subjected to a productivity shock and to an increase in government spending. The net effect of government spending can then be computed by subtracting the economy's response in the baseline scenario from its response in the alternative scenario. Figure 9 shows the effects of a $1 \%$ increase in government spending conditional on a positive and a negative productivity shock of equal size, identical to those considered in the previous section $( \pm 1 \%)$.

Figure 9 shows that the response of aggregate output to the spending shock is larger in recession

${ }^{19}$ To see this, notice that unemployment evolves according to

$$
u_{t+1}=s\left(1-u_{t}\right)+\left(1-f_{t}\right) u_{t}
$$

Thus, the effect of a fall in $f_{t}$ on $u_{t+2}$ is amplified by the fact that $u_{t+1}$ rises in recession ( $u_{t}$ is predetermined), whereas the effect of an increase in $f_{t}$ on $u_{t+2}$ is offset by the fact that $u_{t+1}$ falls in expansion.

${ }^{20} \mathrm{On}$ the other hand, the fact that the matching function exhibits decreasing marginal returns to vacancies implies that, ceteris paribus, labor-market tightness increases more in response to positive productivity shocks than it falls in response to adverse shocks (see Hairault, Langot, and Osotimehin (2010) for further discussion). Nonetheless, in general equilibrium, the job-finding probability falls more in recession than it increases in expansion. 
than in expansion. The present-value output multiplier is 0.82 in the latter case and 1.07 in the former (see the first row of Table 3 ). The difference of $30 \%$ reflects both the larger response of aggregate consumption and the larger decline in the unemployment rate at short and medium horizons. This state dependence results from the joint influence of the matching frictions, the precautionary motive, and the composition effect. As the pool of job seekers is larger during downturns than during expansions (due to the non-linearity of the effects of productivity shocks), the concavity of the job-finding probability implies that employment increases more in the former case than in the latter, in response to a given increase in government spending. ${ }^{21}$ Because unemployment risk is reduced substantially more when government spending occurs while the economy is in recession, employed and unemployed households curtail their precautionary saving by a larger amount, leading to a smaller crowding-out of aggregate consumption at short horizons and a larger crowding-in at medium horizons. The larger reduction in the fraction of low-consumption households in total population further contributes to the difference in the consumption response between expansion and recession. Under our calibration, the present-value consumption multiplier is positive in recession, implying an output multiplier that exceeds 1.

The arguments just discussed suggest that the aggregate effects of public spending are not just asymmetric in good and bad times but that they are also more highly non-linear in the size of recessions than in the size of expansions. To illustrate this property, we compute the spending multiplier for aggregate output, unemployment, aggregate consumption, and the per capita consumption of employed and unemployed households conditional on different sizes of the productivity shock, ranging from $-1.15 \%$ to $1.15 \%$. The results are depicted in Figure 10. The number obtained when the value of the productivity shock is nil is simply the unconditional multiplier. For output, this would be the value reported in the first row of Table 2 .

Figure 10 clearly shows the state dependence of the spending multiplier. For all the variables shown in the figure, the multiplier conditional on a negative productivity shock is larger (in absolute value) than the multiplier conditional on a positive shock of the same size. Interestingly, the multiplier for the consumption of unemployed households is always positive, whereas that for the consumption of employed households is always negative when the spending shock occurs in an expansion, but flips sign when the economy is in a sufficiently severe recession. Together, these two observations imply that the aggregate consumption multiplier can be positive even for relatively mild recessions. In our economy, this is the case as long as the recession is caused by an initial decline in productivity that exceeds $0.85 \%$.

Figure 10 also shows that the spending multipliers are decreasing (in absolute value) and highly convex in the size of the productivity shock. Put differently, the multipliers increase exponentially

\footnotetext{
${ }^{21}$ Graphically, when the economy is in a recession, it lies on the steep portion of the curve representing the jobfinding probability as a function of market tightness, whereas it lies on the flat portion of the curve when it is in an expansion.
} 
Figure 9: Impulse responses to a $1 \%$ government spending shock. Net effect in recession and expansion.

(a) Output

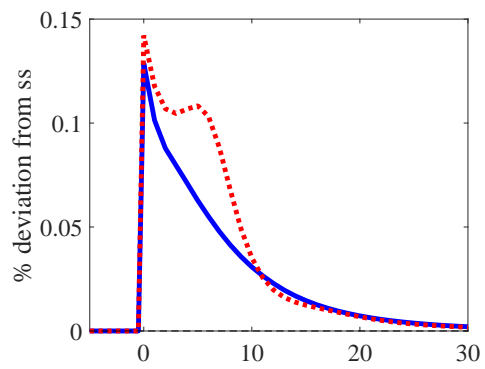

(d) Aggregate consumption

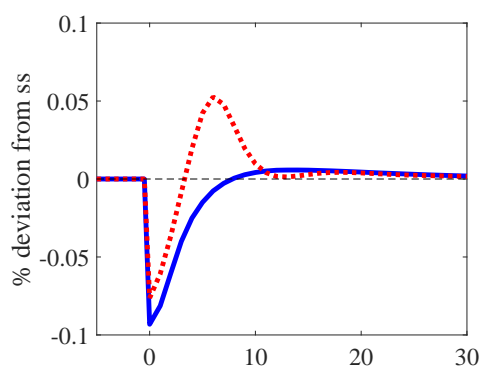

(g) Job finding probability

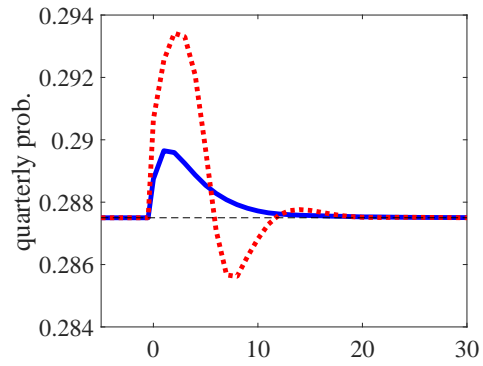

(b) Hours worked

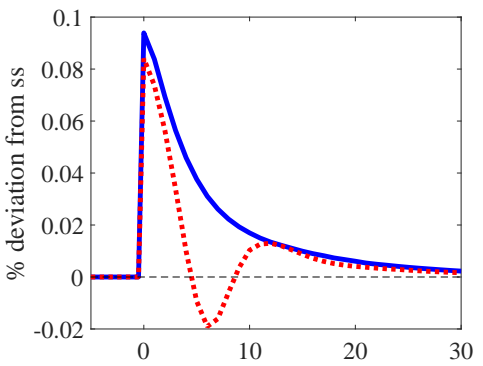

(e) Consumption (empl.)

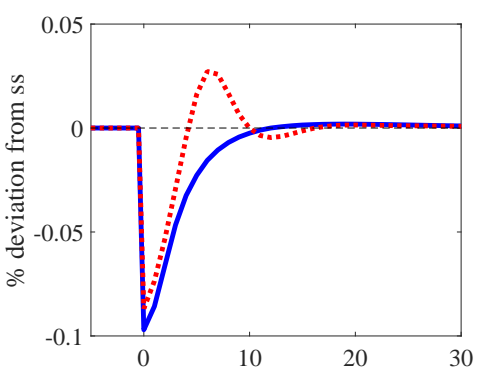

(h) Real interest rate

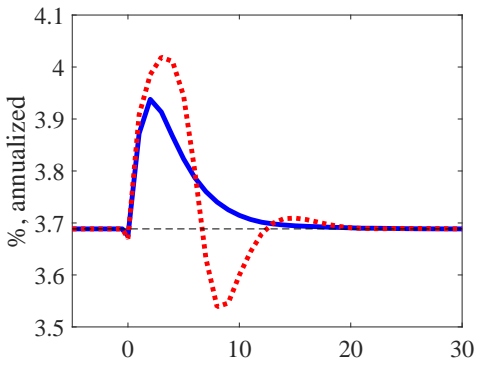

(c) Unemployment

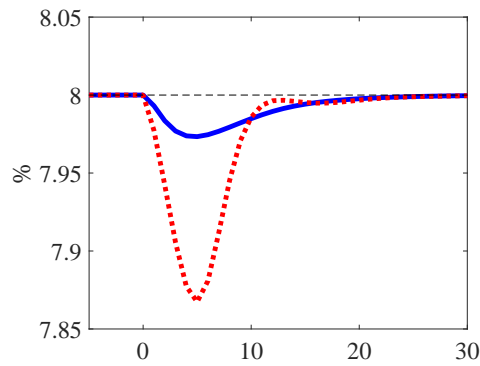

(f) Consumption (unempl.)

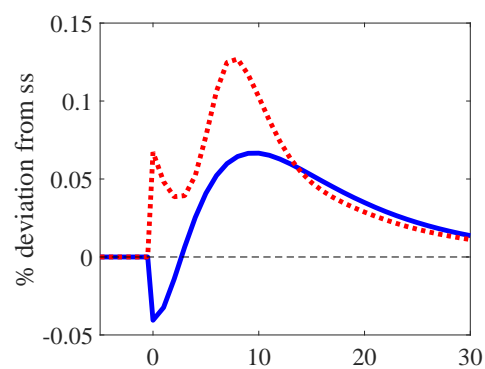

(i) Debt to GDP

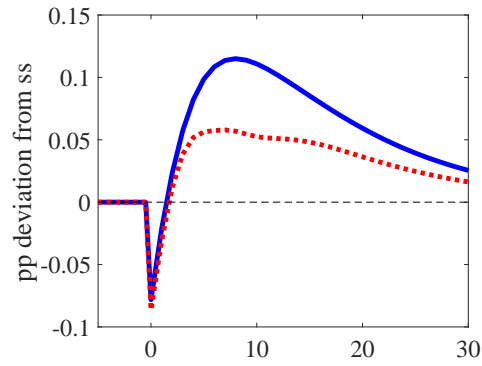

Solid blue: conditional on an expansion. Dotted red: conditional on a recession.

Table 3: State-dependent output multipliers.

\begin{tabular}{lccr}
\hline \hline & \multicolumn{3}{c}{ Present-value multiplier } \\
\cline { 2 - 4 } & Expansion & Recession & Difference \\
\hline Benchmark economy & 0.8249 & 1.0738 & $30.18 \%$ \\
Variants & & & \\
$\quad$ No composition effect & 0.8016 & 0.9826 & $22.58 \%$ \\
Complete markets & 0.6293 & 0.6552 & $4.11 \%$ \\
No intensive margin & 0.2842 & 0.4698 & $65.26 \%$ \\
Flexible prices & 0.6961 & 0.6658 & $-4.35 \%$ \\
Tax financing & 0.6784 & 1.0212 & $50.55 \%$ \\
\hline
\end{tabular}

Note: Expansions (resp. recessions) are generated by assuming that the economy is hit by a $1 \%$ positive (resp. negative) productivity shock, except for the case with no intensive margin, in which the size of the productivity shock is reduced to $\pm 0.5 \%$. 
Figure 10: Present-value multipliers conditional on productivity shocks

(a) Output

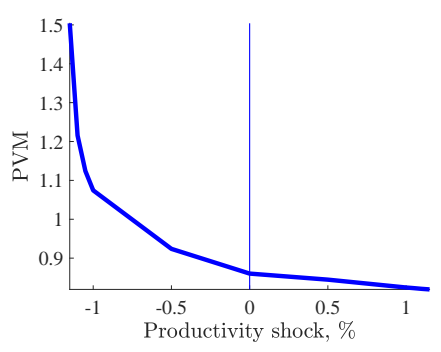

(b) Unemployment

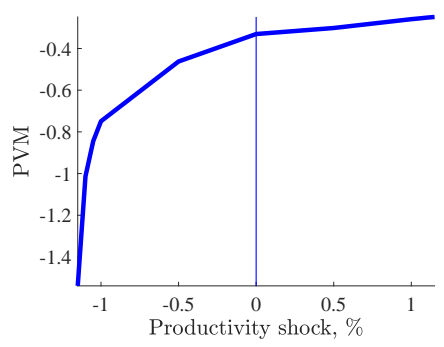

(c) Aggregate consumption

(d) Consumption (empl.)

(e) Consumption (unempl.)
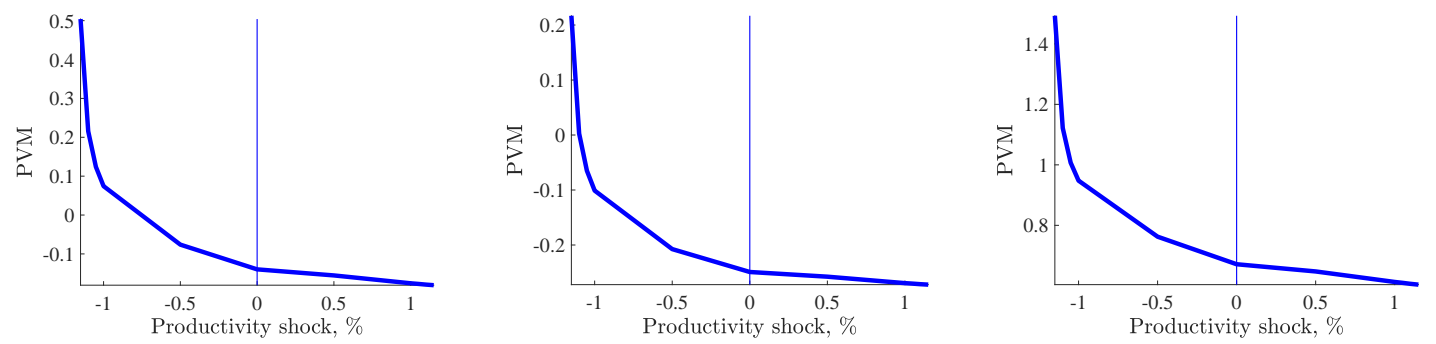

Notes: Present-value multiplier are computed according to Equation 24 with $x_{t}$ being the variable of interest. The productivity shock ranges from -0.0115 to 0.0115 .

with the severity of the recession but decrease fairly linearly with the size of the expansion. This strong curvature implies that the state dependence of the effects of government spending becomes increasingly salient when business-cycle fluctuations become more volatile, exhibiting higher peaks and deeper troughs. For instance, the present-value output multiplier surges from 0.82 when it is conditional on a $1.15 \%$ positive productivity shock to 1.5 when it is conditional on an equal-size negative productivity shock, an amplification of more than $80 \%$.

Table 3 also shows the output multipliers in recession and expansion obtained from the counterfactual economies discussed in Section 3.2. The size of productivity shocks is the same as in the benchmark economy, except for the model without an intensive margin, in which the size of the shock had to be reduced for our numerical algorithm to converge. Not surprisingly, the spending multipliers in the counterfactual economies are smaller than the benchmark values regardless of whether the economy is in recession or expansion. Relative to the benchmark economy, neutralizing the composition effect only marginally lowers the multiplier conditional on an expansion (from 0.82 to 0.80 ) but significantly reduces the multiplier conditional on a recession (from 1.07 to 0.98 ). As a result, this economy generates a state dependence of roughly $23 \%$, which highlights the importance of the precautionary-saving channel in accounting for the countercyclicality of the spending multiplier. This conclusion is further supported by the fact that the economy with complete insurance markets generates little difference in the multiplier between recessions and expansions (about 4\%).

When we abstract from the intensive margin of labor adjustment, the output multiplier in re- 
cession is $65 \%$ larger than the value obtained in expansion. This is due to the fact that, with constant hours of work, all the necessary adjustment in employment (and the implied effect on unemployment risk) occurs through the extensive margin, and that the latter is highly asymmetric due to the concavity of employment with respect to market tightness. Note, however, that while the difference in the multiplier is large in relative terms, the size of the multiplier in this economy remains small, even during recessions. A version of the model in which prices are fully flexible generates an inverted state dependence, with a larger output multiplier in expansion than in recession. This result can be easily understood by recalling that, under price flexibility, an increase in government spending raises unemployment and, by extension, unemployment risk.

Finally, when the increase in public spending is financed using lump-sum taxes, the conditional multipliers are lower than in the benchmark economy (see Section 3.3) but exhibit larger state dependence. The chief reason for the latter result is that recessions and expansions are amplified by the constant-debt fiscal rule. Indeed, when the supply of bonds varies endogenously and lump sum taxes change gradually, the unemployment insurance system serves as a built-in automatic stabilizer that attenuates the size of expansions/recessions. When public debt is constrained to remain constant, on the other hand, current unemployment benefits can only be financed by levying current taxes, which lowers employed households' disposable income by a larger amount.

\subsection{Sensitivity analysis}

In this section, we study the sensitivity of our results along two dimensions. First, we consider alternative values of the following parameters, one at a time: the replacement rate, $h$; the matchingcurvature parameter, $\alpha$; the inverse of the Frisch elasticity of labor supply, $\psi$; and the tax-feedback parameter, $d_{T}$. In each case, we evaluate the present-value multiplier for aggregate output, unemployment, aggregate consumption, and the per capita consumption of employed and unemployed households conditional on different sizes of the productivity shock. The results are depicted in Figure 11. Second, we calibrate the model to represent the U.S. labor market.

\subsubsection{Alternative parameter values}

As an alternative value for the replacement rate, we choose $h=0.4$, a value commonly used in search and matching models calibrated to the U.S. economy, which arguably has a lower replacement rate than most of European countries. All else equal, lower replacement rate has two effects. First, it exacerbates income losses during unemployment spells, which strengthens the precautionarysaving motive. To the extent that an increase in government spending reduces unemployment, a lower replacement rate will lead to a smaller fall in the per capita consumption of unemployed households and thus to a larger spending multiplier. Second, because the replacement rate pins down the vacancy-posting cost (conditional on the values of the remaining parameters), the latter 
increases (from $0.4524 \bar{w}$ to $0.6831 \bar{w}$ ) when $h$ falls (from 0.6 to 0.4 ). Larger vacancy-posting costs imply that firms' accounting profits are larger and less sensitive (in terms of percentage changes) to shocks, mitigating firm's incentives to post vacancies, ${ }^{22}$ and by extension, the fall in unemployment following an increase in government spending (as in Monacelli, Perotti, and Trigari (2010)). This in turn translates into a smaller output multiplier. During expansions and relatively benign recessions, the first effect dominates, such that a lower replacement rate raises the spending multiplier. For deeper recessions, the second effect dominates, reducing the multiplier when the replacement rate is lower. The reason for this result lies in the fact that lower replacement rates dampen the response of output and unemployment to productivity shocks, and that this dampening is larger the more negative is the shock. Together, these results imply that the extent of state dependence falls with the replacement rate. Figure 11 shows that when $h=0.4$, the difference in the spending multipliers between recessions and expansions is negligible.

Figure 11: Sensitivity analysis: Conditional present-value multipliers under alternative parameter values.

(a) Output

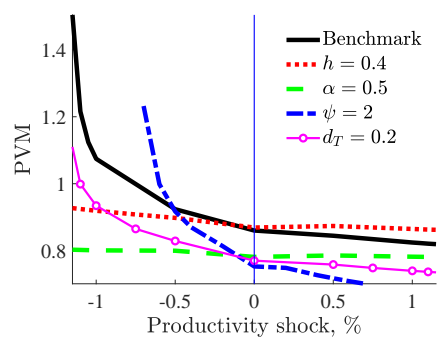

(b) Unemployment

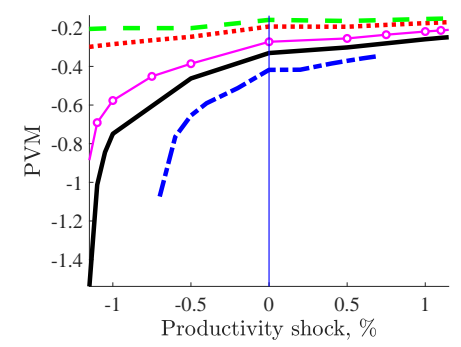

(c) Aggregate consumption

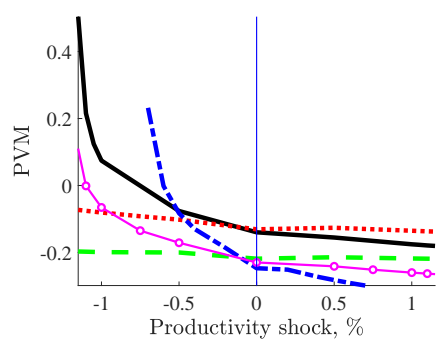

(d) Consumption (empl.)

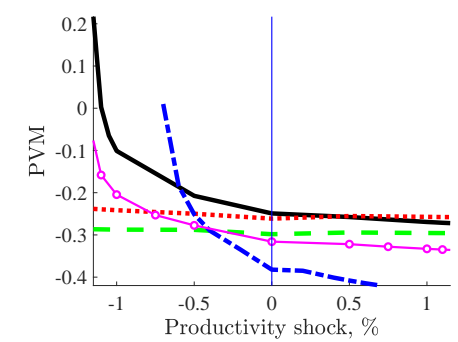

(e) Consumption (unempl.)

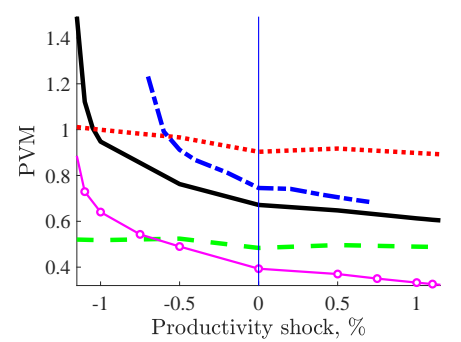

Note: Present-value multipliers are computed according to Equation 24 with $x_{t}$ being the variable of interest.

Next, we lower the matching-curvature parameter, $\alpha$, from its benchmark value of 1.25 to a value of 0.5. As shown in Figure 11, the spending multiplier falls (rises for unemployment) for any given value of the productivity shock. This is simply due to the fact that a smaller value of $\alpha$ implies a smaller job-finding probability for any given labor-market tightness. More importantly, the figure shows that the spending multiplier becomes essentially insensitive to the size of recessions/expansions. The reason is that the job-finding probability becomes nearly linear with

\footnotetext{
${ }^{22}$ See Hagedorn and Manovskii (2008).
} 
respect to the labor-market tightness. In our model, the concavity of the job-finding probability plays a key role in generating asymmetric changes in unemployment, which translate into asymmetries in precautionary saving and in the composition effect. ${ }^{23}$ With a nearly linear job-finding probability, these asymmetries essentially vanish. This suggests that search and matching frictions are a prerequisite to generate countercyclical spending multipliers in our economy, though they are not sufficient per se in the context of our model, as shown by our results for the complete-market economy. Only when those frictions are combined with incomplete insurance markets do they give rise to sizable state dependence in the spending multiplier.

In the third experiment, we consider a Frisch elasticity of labor supply of 0.5 by increasing $\psi$ from 1 to 2 . Larger values of $\psi$ imply that the union is less willing to increase the supply of hours after a given shock, ceteris paribus. As $\psi$ tends to infinity, the model boils down to the economy without an intensive margin of labor adjustment, described in Section 3.2. By a continuity argument, it is obvious that the unconditional output multiplier will be smaller the larger the value of $\psi$. This continues to be the case in expansions and in benign recessions. However, because larger values of $\psi$ amplify the economy's response to productivity shocks, recessions will be more severe for a given fall in productivity, and this tends to increase the multiplier and thus the extent of state dependence.

Finally, we increase the value of the tax-feedback parameter, $d_{T}$, from 0.1 to 0.2 . This alternative parameter value tilts the tax schedule needed to finance the increase in government spending towards the present. Since Ricardian equivalence does not hold in our model, this further raises the real interest rate and exacerbates the fall in the consumption of employed households at short horizons. Because the present-value multiplier assigns a larger weight to changes in aggregate variables that occur in the near future, it will tend to decrease (in absolute value) as $d_{T}$ rises. This outcome should hold regardless of the size of productivity shocks since $d_{T}$ has little effect on the economy's response to those shocks. One should therefore expect the multiplier curves to simply shift downward (upward for unemployment) compared to the benchmark economy, which is exactly what Figure 11 shows. Based on this discussion, we can safely conclude that the amount of state dependence implied by the model exhibits very little sensitivity to changes in the value of $d_{T}$.

\subsubsection{Calibrating the model to the U.S. labor market}

So far, we have focused on a model that captures the specificities of the labor market prevailing in major European countries, and studied the sensitivity of results by perturbating some of the structural parameters one at a time. In what follows, we evaluate the spending multiplier and its state dependence in a version of the model that is calibrated to the U.S. economy. The U.S. labor

\footnotetext{
${ }^{23}$ Conceptually, the parameters $h$ and $\alpha$ affect the results through the same channel: the elasticity of unemployment in response to shocks. However, while changes in $h$ affect this elasticity indirectly — through steady-state tightness - changes in $\alpha$ do so directly.
} 
market is not only characterized by a lower replacement rate than our benchmark economy, it also features significantly larger separation and job-finding rates, i.e., larger labor-market turnover. ${ }^{24}$ To capture these characteristics, we set the replacement rate to $h=0.4$ and impose a separation rate of $s=0.05$ - twice the benchmark value, along with a targeted unemployment rate of $u=0.059$, which yields a job-finding probability $f \simeq 0.8$ - almost four times the benchmark value. These numbers are almost identical to those used by Challe (2018), who targets the U.S. labor market at a quarterly frequency.

Keeping the remaining parameters unchanged, we obtain the stationary distributions and policy functions reported in Figure 12. Compared with the results based on the European calibration, the higher transition rates produce much more similar stationary distributions of asset holdings for employed and unemployed households. These distributions indicate that a much smaller number of unemployed households hold zero assets: since unemployment spells are much shorter, unemployed households get to keep a larger fraction of the (precautionary) asset holdings they accumulated in the past, when they were employed. Note that this feature tends to lower the aggregate MPC of unemployed households. In addition, employed households accumulate less assets to self-insure against unemployment risk since the higher turnover tends to reduce unemployment risk, even though the income loss associated with unemployment spells is larger than under the European calibration. Figure 12 also reveals that the consumption function is steeper at low levels of asset holdings under the U.S. calibration, especially for unemployed households, implying that these households have a larger marginal utility of consumption at low levels of assets than their counterparts in the benchmark economy. Importantly, this feature tends to raise the MPC of unemployed households holding small amounts of assets, and thus the aggregate MPC of unemployed households.

How does the U.S. calibration affect the degree of state dependence of the spending multipliers? To answer this question, we again evaluate the net effects of a government spending shock conditional on positive and negative productivity shocks. The responses obtained in each state are reported in Figure 13. These responses resemble those obtained under the European calibration: An increase in government spending raises aggregate demand and lowers unemployment. The job-finding probability increases and unemployment risk drops, which eventually crowds-in the consumption of unemployed households, thus fueling the rise in aggregate demand and further lowering unemployment. These effects are larger conditional on a recession than on an expansion. Quantitatively, the output multiplier is 0.73 in expansion and 0.86 in recession, a difference of 18\%. This amount of state dependence, albeit smaller than under the European calibration is still significant.

\footnotetext{
${ }^{24}$ From this perspective, the alternative calibration of the replacement rate performed in the sensitivity analysis above, while informative, would be insufficient to draw conclusions about the effects of government spending shocks and their state dependence in the U.S. simply because other parameters need to be simultaneously re-calibrated to match the characteristics of the U.S. labor market.
} 
Figure 12: Steady-state distributions and policy functions for the U.S. calibration.
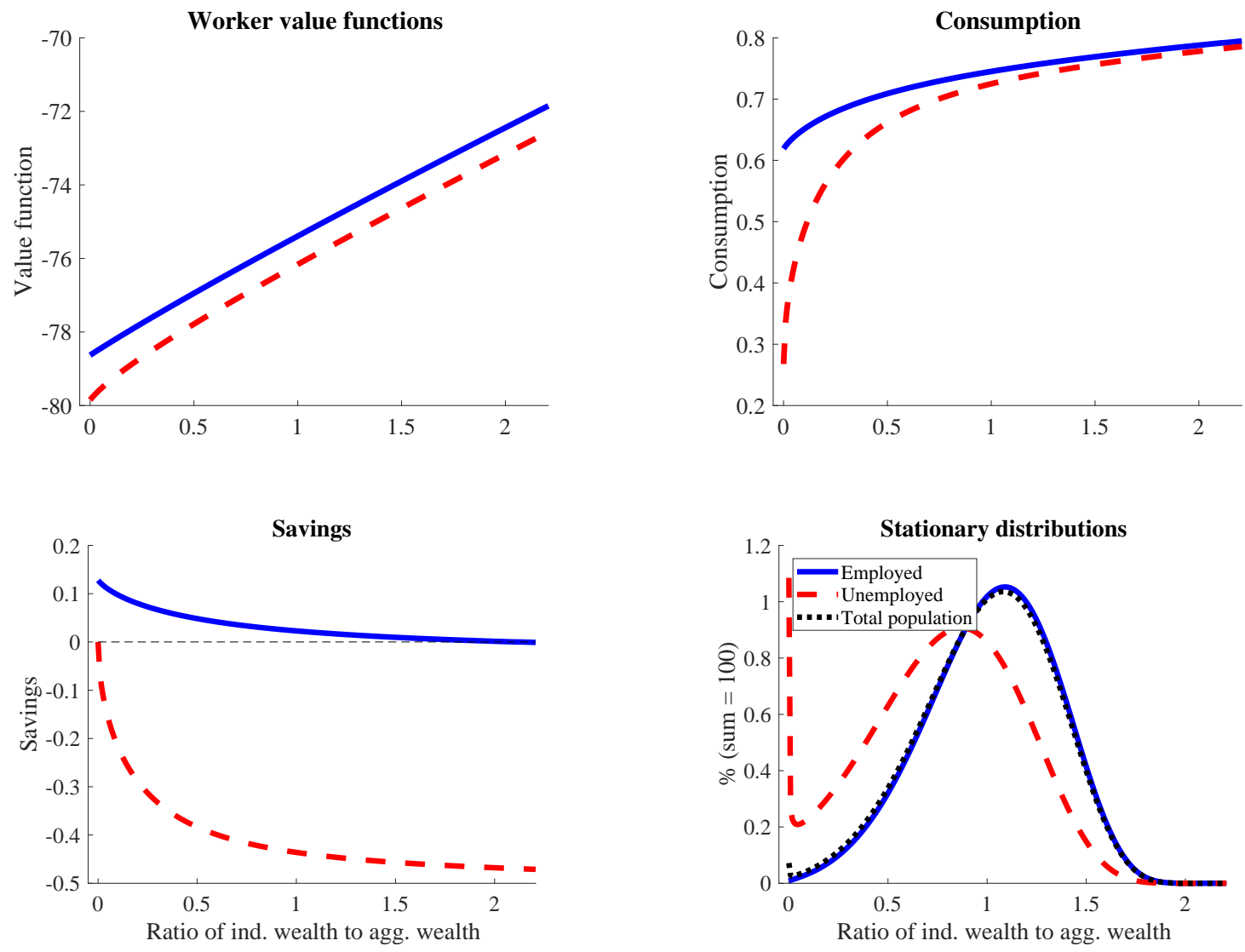
To understand why the model is capable of generating large and countercyclical spending multipliers even in a high-turnover labor market, it is important to notice that what matters for our findings is the sensitivity of precautionary saving to cyclical fluctuations. Under the European calibration, this sensitivity stems from the fact that unemployed households hold a relatively low level of precautionary saving, which tends to change significantly in percentage terms for a given change in the job-finding probability. Under the U.S. calibration, on the other hand, the precautionary saving of unemployed households is relatively large but the job-finding probability is more responsive to shocks than under the European calibration in any given state.

Figure 13: Impulse responses to a $1 \%$ government spending shock. Net effect in recession and expansion. U.S. calibration.

(a) Output

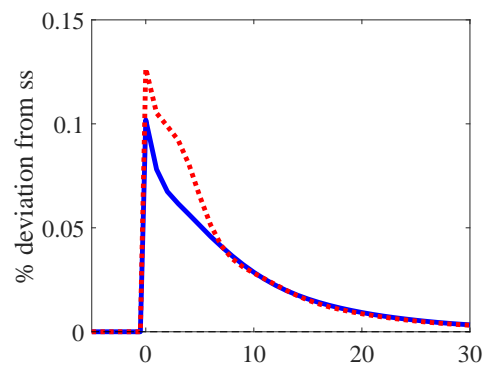

(d) Aggregate consumption

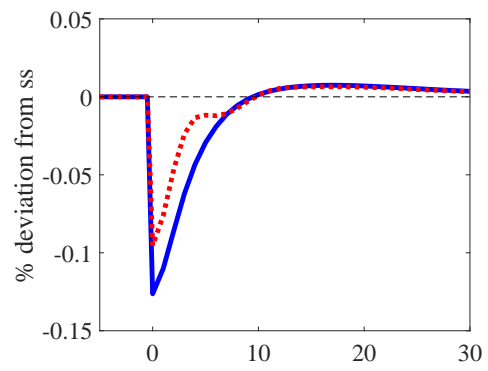

(g) Job finding probability

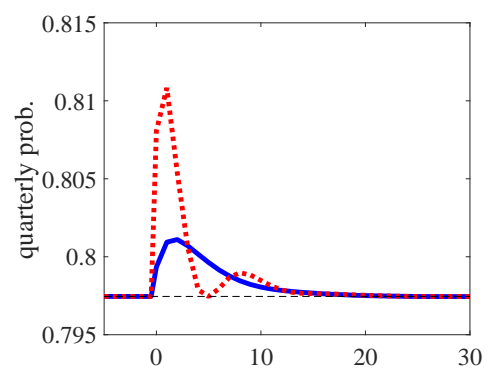

(b) Hours worked

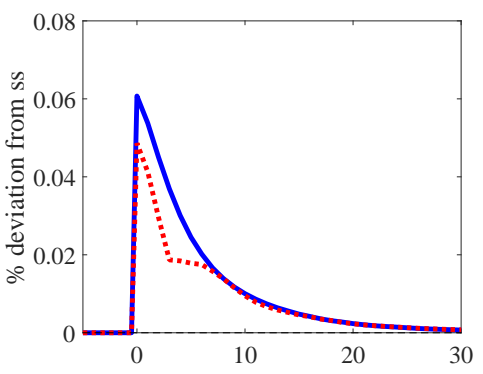

(e) Consumption (empl.)

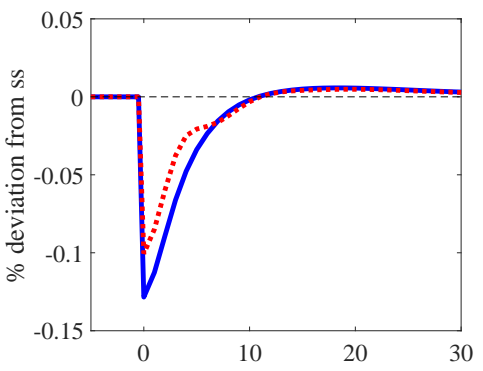

(h) Real interest rate

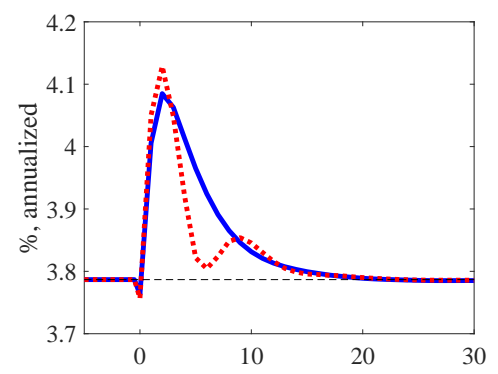

(c) Unemployment

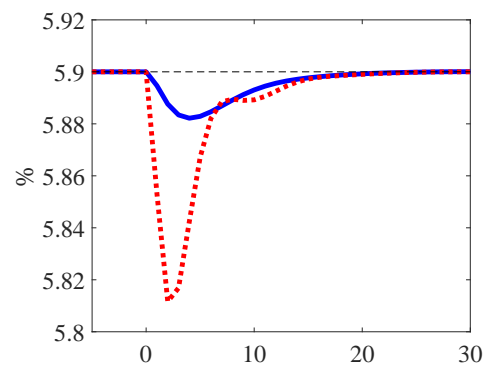

(f) Consumption (unempl.)

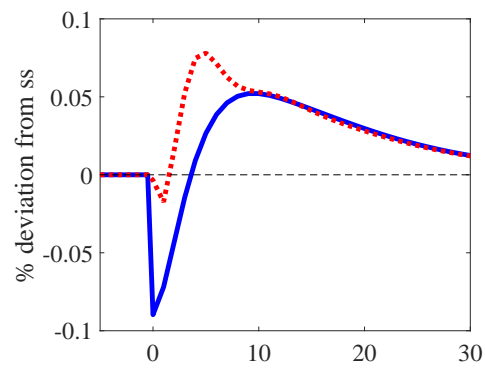

(i) Debt to GDP

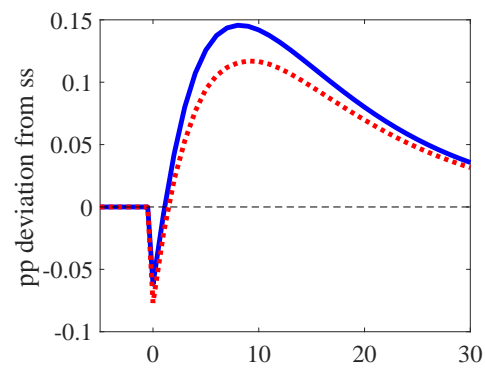

Solid blue: conditional on an expansion. Dotted red: conditional on a recession. 


\section{Concluding Remarks}

In this paper, we have developed a model with involuntary unemployment, incomplete markets and nominal rigidity, in which government spending increases labor-market tightness and lowers unemployment. Because markets are incomplete, precautionary saving and changes in the fraction of unemployed households in the population amplify the aggregate effects of government spending. The non-linearity arising from endogenous variations in unemployment risk implies that those effects are state dependent, with spending multipliers being larger in recessions than in expansions. In particular, the output and consumption multipliers increase exponentially with the size of the recession but fall linearly with the size of the expansion. The extent of state dependence generated by the model is substantially larger than that obtained from an otherwise identical economy in which unemployment risk is fully insured.

The mechanism put forward in this paper is certainly not the only channel through which spending multipliers can exhibit state dependence; some earlier studies have succeeded in generating highly countercyclical multipliers - even exceeding 1 in recession — without relying on incomplete insurance against unemployment risk, such that household heterogeneity is materially irrelevant for aggregate consumption and output. However, by taking into consideration unemployment risk, our framework contains the key ingredients to analyze other aspects of fiscal policy for which household heterogeneity is of first-order importance — such as social transfers and unemployment insurance. Those questions, as well as the normative implications of our results, are left for future research. 


\section{References}

Albertini, Julien and Xavier Fairise. 2013. "Search Frictions, Real Wage Rigidities and the Optimal Design of Unemployment Insurance." Journal of Economic Dynamics and Control 37 (9):17961813.

Auerbach, Alan J. and Yuriy Gorodnichenko. 2012a. "Measuring the Output Responses to Fiscal Policy." American Economic Journal: Economic Policy 4 (2):1-27.

— 2012b. "Fiscal Multipliers in Recession and Expansion." In Fiscal Policy after the Financial Crisis, NBER Chapters. National Bureau of Economic Research, Inc, 63-98.

Bachmann, Rüdiger and Eric R. Sims. 2012. "Confidence and the Transmission of Government Spending Shocks." Journal of Monetary Economics 59 (3):235-249.

Baum, Anja, Marcos Poplawski-Ribeiro, and Anke Weber. 2012. "Fiscal Multipliers and the State of the Economy." IMF Working Paper 12/286.

Bayer, Christian, Ralph Luetticke, Lien Pham-Dao, and Volker Tjaden. 2019. "Precautionary Savings, Illiquid Assets, and the Aggregate Consequences of Shocks to Household Income Risk." Econometrica 87 (1):255-290.

Beaudry, Paul, Dana Galizia, and Franck Portier. 2018. "Reconciling Hayek's and Keynes' Views of Recessions." Review of Economic Studies 85 (1):119-156.

Bilbiie, Florin O. 2008. "Limited Asset Markets Participation, Monetary Policy and (Inverted) Aggregate Demand Logic." Journal of Economic Theory 140 (1):162-196.

—. 2019. "The New Keynesian Cross." Journal of Monetary Economics :Forthcoming.

Blanchard, Olivier and Jordi Galí. 2010. "Labor Markets and Monetary Policy: A New Keynesian Model with Unemployment." American Economic Journal: Macroeconomics 2 (2):1-30.

Candelon, Bertrand and Lenard Lieb. 2013. "Fiscal Policy in Good and Bad Times." Journal of Economic Dynamics and Control 37 (12):2679-2694.

Canzoneri, Matthew, Fabrice Collard, Harris Dellas, and Behzad Diba. 2016. "Fiscal Multipliers in Recessions." Economic Journal 126 (590):75-108.

Carroll, Christopher D., Jiri Slacalek, and Kiichi Tokuoka. 2014. "The Distribution of Wealth and the MPC: Implications of New European Data." American Economic Review 104 (5):107-111.

Challe, Edouard. 2018. "Uninsured Unemployment Risk and Optimal Monetary Policy." American Economic Journal: Macroeconomics Forthcoming.

Christiano, Lawrence, Martin Eichenbaum, and Sergio Rebelo. 2011. "When Is the Government Spending Multiplier Large?" Journal of Political Economy 119 (1):78 - 121.

Daeha, Cho. 2020. "Unemployment Risk, MPC Heterogeneity, and Business Cycles." mimeo .

den Haan, Wouter J., Garey Ramey, and Joel Watson. 2000. "Job Destruction and Propagation of Shocks." American Economic Review 90 (3):482-498.

Eggertsson, Gauti B. 2011. "What Fiscal Policy is Effective at Zero Interest Rates?" In NBER Macroeconomics Annual 2010, Volume 25, NBER Chapters. National Bureau of Economic Research, Inc, 59-112.

Elsby, Michael W. L., Bart Hobijn, and Ayşegül Şahin. 2013. "Unemployment Dynamics in the OECD." The Review of Economics and Statistics 95 (2):530-548. 
Esser, Ingrid, Tommy Ferrarini, Kenneth Nelson, Joakim Palme, and Ola Sjüberg. 2013. "Unemployment Benefits in EU Member States." European Commission Working Paper 15.

Fazzari, Steven M., James Morley, and Irina Panovska. 2015. "State-dependent Effects of Fiscal Policy." Studies in Nonlinear Dynamics 83 Econometrics 19 (3):285-315.

Furceri, Davide and Bin Grace Li. 2017. "The Macroeconomic (and Distributional) Effects of Public Investment in Developing Economies." IMF Working Paper 17/217.

Galí, Jordi, Mark Gertler, and J. David López-Salido. 2007. "Markups, Gaps, and the Welfare Costs of Business Fluctuations." The Review of Economics and Statistics 89 (1):44-59.

Galí, Jordi, J. David López-Salido, and Javier Vallés. 2007. "Understanding the Effects of Government Spending on Consumption." Journal of the European Economic Association 5 (1):227-270.

Gechert, Sebastian and Ansgar Rannenberg. 2018. "Which Fiscal Multipliers are RegimeDependent? A Meta Regression Analysis." Journal of Economic Surveys 32 (4):1160-1180.

Gornemann, Nils, Keith Kuester, and Makoto Nakajima. 2016. "Doves for the Rich, Hawks for the Poor? Distributional Consequences of Monetary Policy." CEPR Discussion Paper 11233.

Hagedorn, Marcus and Iourii Manovskii. 2008. "The Cyclical Behavior of Equilibrium Unemployment and Vacancies Revisited." American Economic Review 98 (4):1692-1706.

Hagedorn, Marcus, Iourii Manovskii, and Kurt Mitman. 2019. "The Fiscal Multiplier." NBER Working Paper 25571.

Hairault, Jean-Olivier, Francois Langot, and Sophie Osotimehin. 2010. "Matching frictions, unemployment dynamics and the cost of business cycles." Review of Economic Dynamics 13 (4):759779 .

Kaplan, Greg, Benjamin Moll, and Giovanni L. Violante. 2018. "Monetary Policy According to HANK." American Economic Review 108 (3):697-743.

Kaplan, Greg and Giovanni L. Violante. 2018. "Microeconomic Heterogeneity and Macroeconomic Shocks." Journal of Economic Perspectives Forthcoming.

Krause, Michael U. and Thomas A. Lubik. 2007. "The (Ir)relevance of Real Wage Rigidity in the New Keynesian Model with Search Frictions." Journal of Monetary Economics 54 (3):706-727.

Krusell, Per, Toshihiko Mukoyama, and Ayşegül Şahin. 2010. "Labour-Market Matching with Precautionary Savings and Aggregate Fluctuations." Review of Economic Studies 77 (4):14771507.

Krusell, Per and Anthony A. Jr. Smith. 1998. "Income and Wealth Heterogeneity in the Macroeconomy." Journal of Political Economy 106 (5):867-896.

Luetticke, Ralph. 2019. "Transmission of Monetary Policy with Heterogeneity in Household Portfolios." Tech. rep. Manuscript.

McKay, Alisdair and Ricardo Reis. 2016. "Optimal Automatic Stabilizers." NBER Working Paper 22359.

Michaillat, Pascal. 2014. "A Theory of Countercyclical Government Multiplier." American Economic Journal: Macroeconomics 6 (1):190-217.

Michaillat, Pascal and Emmanuel Saez. 2018. "Optimal Public Expenditure with Inefficient Unemployment." The Review of Economic Studies 86 (3):1301-1331. 
Mittnik, Stefan and Willi Semmler. 2012. "Regime Dependence of the Fiscal Multiplier." Journal of Economic Behavior \& Organization 83 (3):502-522.

Monacelli, Tommaso, Roberto Perotti, and Antonella Trigari. 2010. "Unemployment Fiscal Multipliers." Journal of Monetary Economics 57 (5):531-553.

Owyang, Michael T., Valerie A. Ramey, and Sarah Zubairy. 2013. "Are Government Spending Multipliers Greater during Periods of Slack? Evidence from Twentieth-Century Historical Data." American Economic Review 103 (3):129-34.

Petrosky-Nadeau, Nicolas and Lu Zhang. 2013. "Unemployment Crises." NBER Working Paper 19207.

Ramey, Valerie A. 2019. "Ten Years after the Financial Crisis: What Have We Learned from the Renaissance in Fiscal Research?" NBER Working Paper 25531.

Ravenna, Federico and Carl E. Walsh. 2008. "Vacancies, Unemployment, and the Phillips Curve." European Economic Review 52 (8):1494-1521.

Ravn, Morten O and Vincent Sterk. 2016. "Macroeconomic Fluctuations with HANK \& SAM: An Analytical Approach." CEPR Discussion Paper 11696.

Roulleau-Pasdeloup, Jordan. 2016. "The Government Spending Multiplier in a Deep Recession." Cahiers de Recherches Economiques du Département d'économie 16.22, Université de Lausanne, Faculté des HEC, Département d'économie.

Shen, Wenyi and Shu-Chun S. Yang. 2018. "Downward Nominal Wage Rigidity and State-dependent Government Spending Multipliers." Journal of Monetary Economics 98:11-26.

Shimer, Robert. 2005. "The Cyclical Behavior of Equilibrium Unemployment and Vacancies." American Economic Review 95 (1):25-49.

Woodford, Michael. 2011. "Simple Analytics of the Government Expenditure Multiplier." American Economic Journal: Macroeconomics 3 (1):1-35. 


\section{Appendix}

\section{A Solution method}

Our solution method is fully non-linear and takes advantage of the continuous-time formulation of the heterogeneous-agent problem solving the Hamilton-Jacobi-Bellman and Kolmogorov forward equations. Our codes are adapted from those of Bence Bardoczy taken from the HACT project page maintained by Benjamin Moll: http://www.princeton.edu/ moll/HACTproject.htm.

\section{A.1 Steady state}

The algorithm solving for the steady state is the following. Starting from initial guesses for the real interest rate, $r$, labor market tightness, $\theta$, and the real wage, $w$ :

1. Compute labor market variables $\{f, q, u, v\}$

2. Compute output $y$, deduce government spending $g$ and public debt $b$ using calibration targets, and compute the tax rate $\tau$

3. Compute profits and deduce the levels of income for employed and unemployed households

4. At the given levels of income and real interest rate:

- Solve the Hamilton-Jacobi-Bellman equation

- Solve the marginal value of a job $J$

- Solve the steady-state Nash-bargaining problem and get $w$

- Adjust the value of $\omega$, the disutility parameter associated to hours worked. Hours worked are normalized to one $(\ell=1)$ in the steady state.

- Update the set of value functions $W, J$ and $w$

5. Solve the Kolmogorov forward equation to recover the distributions of households over the asset grid

6. Check residuals on free entry and goods market clearing conditions

7. Update $r$ and $\theta$ respectively using the residuals of the asset market clearing condition, and those of the free entry condition.

Solving for the steady state takes a few seconds. Before computing the steady state, a similar routine solves for the value of $\xi$ that delivers our calibration targets on the labor market. Then the above routine solves for the steady state for the correctly calibrated value of $\xi$. 


\section{A.2 Transition dynamics}

The algorithm solving for the transition dynamics is the following. Starting from a steady state sequence of the real interest rate $\left\{r_{t}\right\}_{t=1}^{t=T}=r$, labor market tightness $\left\{\theta_{t}\right\}_{t=1}^{t=T}=\theta$ and all the relevant variables:

1. For $t=\{1: T\}$, compute labor market variables $\left\{f_{t}, q_{t}\right\}_{t=1}^{t=T}$ and update the transition matrix $\left\{\Lambda_{t}\right\}_{t=1}^{t=T}$

2. For $t=\{1: T\}$, compute the dynamics of public debt $\left\{b_{t}\right\}_{t=1}^{t=T}$

3. For $t=\{1: T\}$, compute the dynamics of the inflation rate using the Taylor rule, and compute the associated path for the nominal interest rate $i_{t}^{n}$

4. For $t=\{T: 1\}$, compute the forward dynamics of the price of intermediate goods $p_{t}^{m}$

5. For $t=\{T: 1\}$, for each $t$ starting from the final (steady-state) allocation:

- Compute profits, lump-sum taxes, and income paths for employed and unemployed households

- Solve the Hamilton-Jacobi-Bellman equations and compute the set of value functions $W_{t}$

- Solve the marginal value of a job $J_{t}$

- Compute the wage according to Equation (8)

- Compute hours worked $\ell_{t}$

6. For $t=\{1: T\}$, solve the Kolmogorov forward equation to obtain the distributions of households over the asset grid for each $t$

7. From those distributions, deduce the unemployment rate $\left\{u_{t}\right\}_{t=1}^{t=T}$ and vacancies $\left\{v_{t}\right\}_{t=1}^{t=T}$ from $\left\{v_{t}\right\}_{t=1}^{t=T}=\left\{\theta_{t}\right\}_{t=1}^{t=T} \times\left\{u_{t}\right\}_{t=1}^{t=T}$.

8. Check residuals on the paths of free entry and asset market clearing conditions

9. Update the paths of $\left\{r_{t}\right\}_{t=1}^{t=T}$ and $\left\{\theta_{t}\right\}_{t=1}^{t=T}$. Let $\left\{\zeta_{\text {asset }, t}\right\}_{t=1}^{t=T}$ denote the path of the excess of asset holdings with respect to the level of public debt and $\left\{\zeta_{f e, t}\right\}_{t=1}^{t=T}$ the path of residuals of the free entry condition. The update process is $\left\{r_{t}^{n e w}\right\}=\left\{r_{t}\right\}-d_{r}\left\{\zeta_{\text {asset }, t}\right\}$ where $d_{r}$ is a small number: whenever households hold assets in excess with respect to asset supply, lower the real interest rate. Similarly, we impose $\left\{\theta_{t}^{\text {new }}\right\}=\left\{\theta_{t}\right\}+d_{\theta}\left\{\zeta_{f e, t}\right\}$ where $d_{\theta}$ is a small number: whenever the labor market is not tight enough, raise tightness $\left\{\theta_{t}\right\}$. Use $\left\{r_{t}^{\text {new }}\right\}$ and $\left\{\theta_{t}^{\text {new }}\right\}$ as new guesses in Step 1, until the largest absolute value of $\left\{\zeta_{\text {asset }, t}\right\}$ and $\left\{\zeta_{f e, t}\right\}$ are less than the tolerance value ( $0.01 \%$ of total asset and $J_{t}$ respectively).

Solving for the transition dynamics takes a few minutes depending on the size and nature of the shocks and the assumptions considered. 


\section{B An extended model}

We propose an extension of the model that comes closer to replicating empirical evidence about the distribution of assets, its dispersion, and the corresponding distribution of MPCs. We introduce two additional sources of heterogeneity. First, we introduce two types of discount factors, one $\rho_{p}<\rho$ that characterizes patient households, whether employed or unemployed, and one $\rho_{i}>\rho$ that characterizes impatient households whether employed or not. In line with Krusell and Smith (1998), households can change discount factor types with a very small probability, which basically amounts to split the population in two roughly equally sized populations of patient and impatient households. This assumption generates a large density of households close to the zero-asset limit, among which many impatient employed households.

The second source of heterogeneity is the addition of a third type of households: entrepreneurs. Instead of assuming that aggregate profits are redistributed to the employed households as in the baseline model, we consider that they are distributed to a specific type of households: entrepreneurs. We introduce a very small probability $p_{e^{+}}$of becoming an entrepreneur and a small probability $p_{e^{-}}>p_{e^{+}}$of losing this status. This implies a relatively low stationary share of entrepreneurs in the economy. Combined with the fact that they receive all the profits from retailers and intermediategood producers, entrepreneurs are very rich in terms of per capita income compared with the other households. They are also large savers because of the probability of losing the status, and the extremely small probability of ever becoming an entrepreneur again in the future, once this status is lost. This additional assumption stretches the distribution of asset holdings to the right - a small fraction of the population becomes asset-rich - and generates a fat right tail in the distribution of asset holdings. Formally, the household's budget constraint in the extended model is

$$
a_{t}^{i}+c_{t}^{i}=\left(1+r_{t-1}\right) a_{t-1}^{i}+\mathbb{1}_{\text {ent }}^{i}\left[\left(1-\tau_{t}\right)\left(\mathbb{1}_{e}^{i} w_{t} \ell_{t}+\left(1-\mathbb{1}_{e}^{i}\right) h \bar{w}\right)-\mathbb{1}_{e}^{i} T_{t}^{i}\right]+\left(1-\mathbb{1}_{\text {ent }}^{i}\right) \Pi_{t}^{i}
$$

where $\mathbb{1}_{e}^{i}$ is an indicator function that takes the value of 1 if household $i$ is employed and 0 otherwise, and $\mathbb{1}_{\text {ent }}^{i}$ an indicator variable that takes the value 1 if household $i$ is an entrepreneur and 0 otherwise. In the extended model, the transition matrix expands because we consider a total of 5 states: employed impatient, unemployed impatient, employed patient, unemployed patient and entrepreneur. Hence,

$$
\Lambda_{t}=\left[\begin{array}{ccccc}
\left(1-p_{e^{+}}\right) p_{o i}(1-s) & \left(1-p_{e^{+}}\right) p_{o i} s & \left(1-p_{e^{+}}\right)\left(1-p_{o i}\right)(1-s) & \left(1-p_{e^{+}}\right)\left(1-p_{o i}\right) s & p_{e^{+}} \\
\left(1-p_{e^{+}}\right) p_{o i} f_{t} & \left(1-p_{e^{+}}\right) p_{o i}\left(1-f_{t}\right) & \left(1-p_{e^{+}}\right)\left(1-p_{o i}\right) f_{t} & \left(1-p_{e^{+}}\right)\left(1-p_{o i}\right) 1-f_{t} & p_{e^{+}} \\
\left(1-p_{e^{+}}\right) p_{n i}(1-s) & \left(1-p_{e^{+}}\right) p_{n i} s & \left(1-p_{e^{+}}\right)\left(1-p_{n i}\right)(1-s) & \left(1-p_{e^{+}}\right)\left(1-p_{n i}\right) s & p_{e^{+}} \\
\left(1-p_{e^{+}}\right) p_{n i} f_{t} & \left(1-p_{e^{+}}\right) p_{n i}\left(1-f_{t}\right) & \left(1-p_{e^{+}}\right)\left(1-p_{n i}\right) f_{t} & \left(1-p_{e^{+}}\right)\left(1-p_{n i}\right) 1-f_{t} & p_{e^{+}} \\
p_{e^{-}} p_{n i} & 0 & p_{e^{-}}\left(1-p_{n i}\right) & 0 & 1-p_{e^{-}}
\end{array}\right]
$$

where recall, $p_{e^{+}}$is the probability of becoming an entrepreneur, $p_{e^{-}}$is the probability of losing the status. In addition, $p_{o i}$ is the (large) probability of staying impatient while $p_{n i}$ is the (small) probability of becoming impatient. We assume that entrepreneurs become workers directly when losing their status. In addition, their discount factor is $\rho$, in-between the discount factor of patient and impatient. 
The rest of the model remains unchanged and the calibration is adapted when needed to deliver similar targets to those in the baseline model. We add a couple of targets: a Gini coefficient on wealth of 0.75 , the upper bound of the numbers available for European economies (see Carroll, Slacalek, and Tokuoka (2014)), and a share of entrepreneurs of 1\%. The latter target is achieved by assuming $p_{e^{+}}=0.001$ and $p_{e^{-}}=0.05$, while we obtain the former by imposing $\rho_{p}=0.0075$, $\rho_{i}=0.015$, along with $p_{o i}=0.995, p_{n i}=0.005$. The corresponding policy functions and stationary distributions are reported in Figure 14.

Figure 14: Steady-state distributions and policy functions in the extended model.
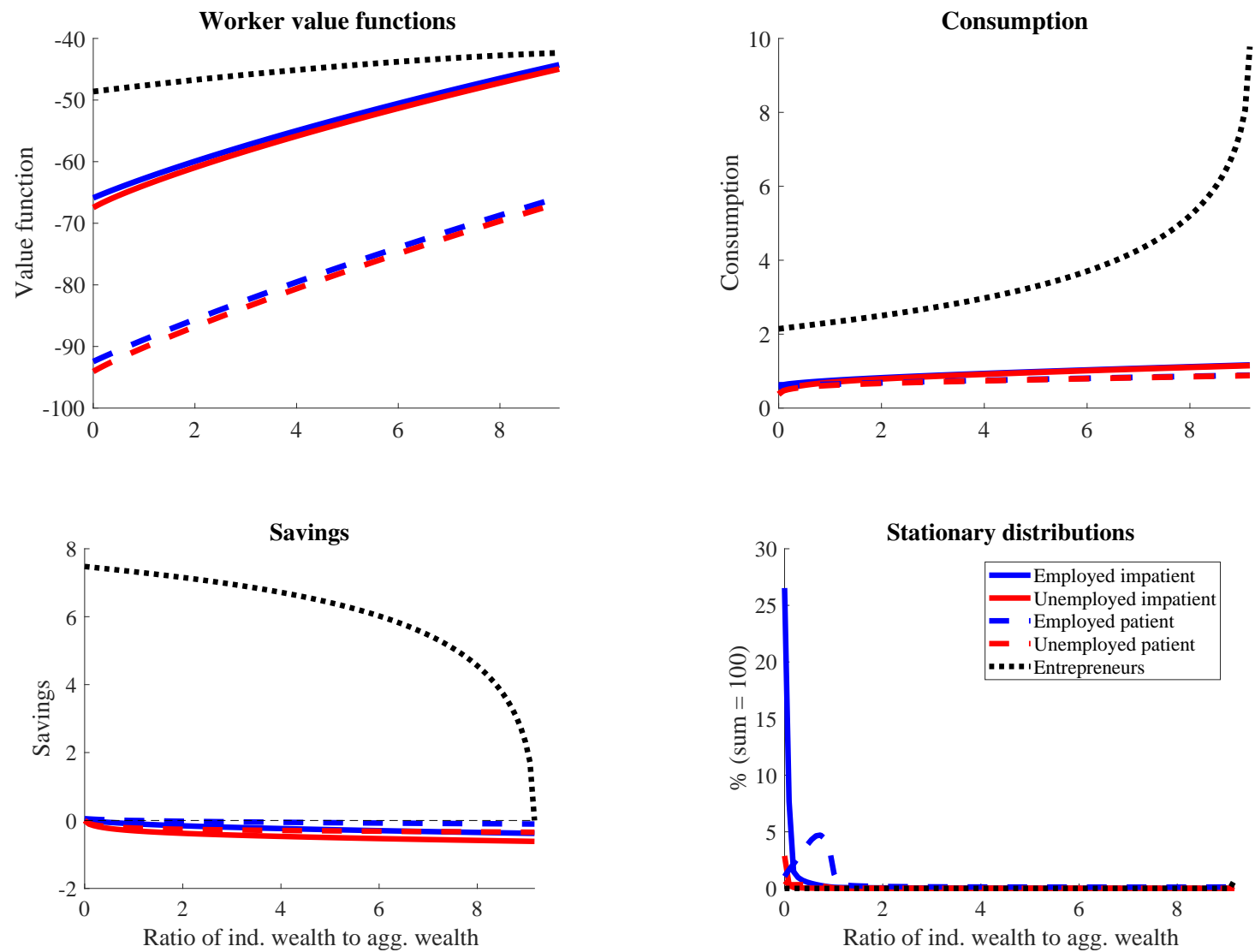

The model delivers a 0.7486 Gini coefficient on wealth, and the Lorenz curve for wealth reported in Figure 15. In addition, the distribution of MPCs is now more in line with empirical evidence, as the aggregate MPC is now 0.2065, the average MPC of impatient unemployed households is 0.5294, the average MPC of patient unemployed 0.4552, and average MPCs are 0.2094 and 0.0147 respectively for impatient and patient employed households. These numbers line-up quite well with those reported by Carroll, Slacalek, and Tokuoka (2014). Finally, we generate impulse responses based on a $\pm 1 \%$ productivity shock and report the net effects of a government spending shock in Figure 16.

Government spending shocks have very similar qualitative implications as in the simpler model, and their effects also display a significant amount of state dependence, government spending im- 
Figure 15: Lorenz curve of wealth in the extended model.

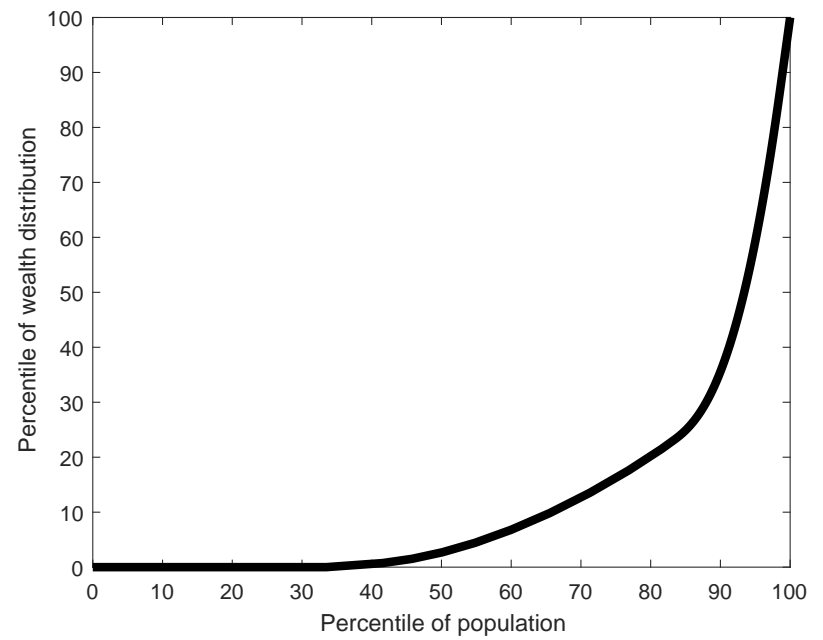

Figure 16: Impulse responses to a $1 \%$ government spending shock in the extended model. Net effect in recession and expansion.

(a) Output

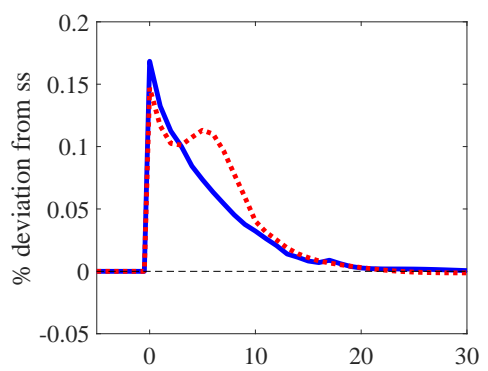

(d) Aggregate consumption

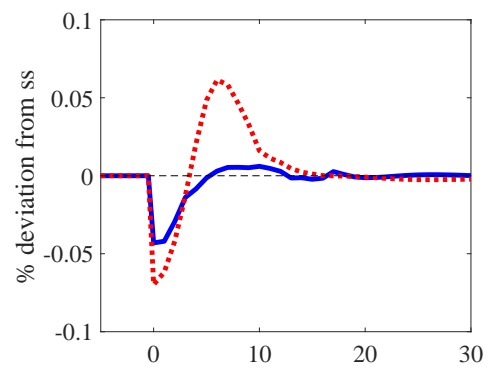

(g) Job finding probability

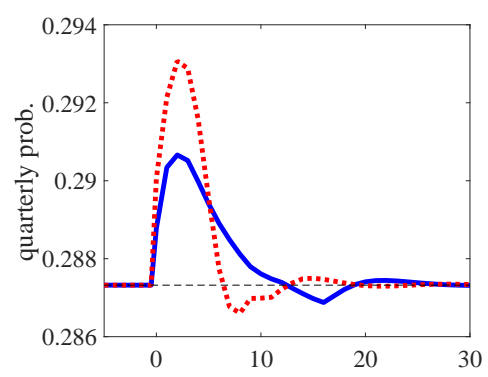

(b) Hours worked

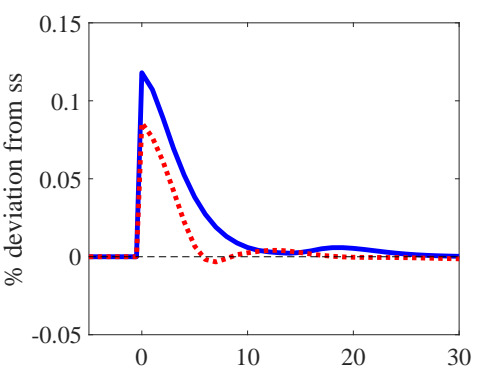

(e) Consumption (empl.)

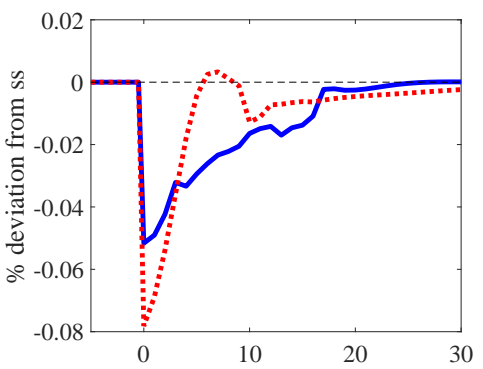

(h) Real interest rate

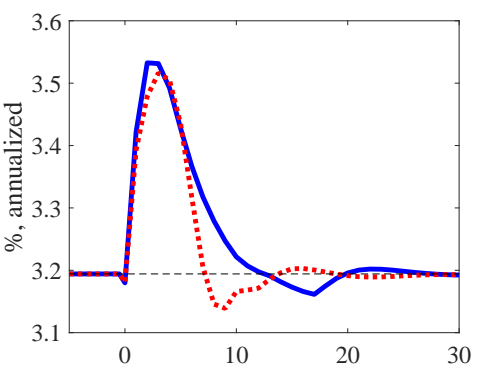

(c) Unemployment

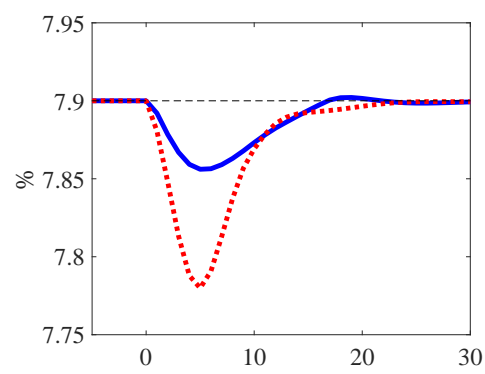

(f) Consumption (unempl.)

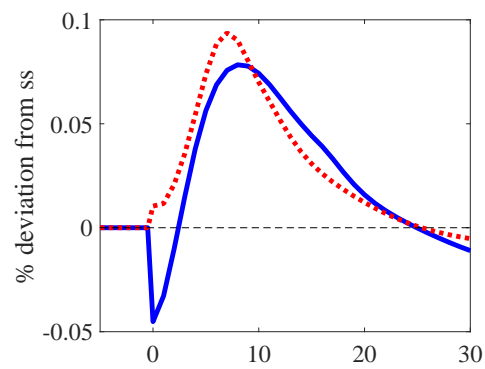

(i) Debt to GDP

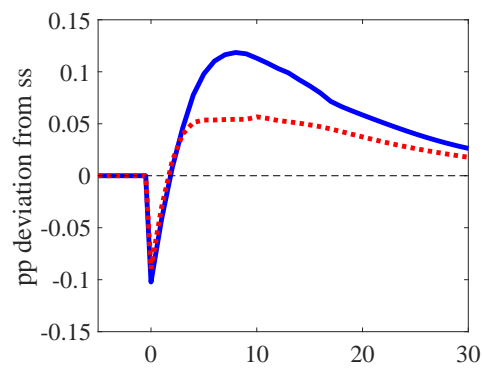

Solid blue: conditional on an expansion. Dotted red: conditional on a recession. 
plying a larger effect on output in a recession than in an expansion. The output multiplier is 0.8740 conditional on a $1 \%$ positive productivity shock (expansion) and 1.0284 conditional on a $1 \%$ negative shock (recession), a difference of $17.67 \%$. These numbers suggest a large amount of state dependence, based on the very same mechanisms than in the baseline model. 